UNITED STATES DEPARTMENT OF THE INTERIOR

GEOLOGICAL SURVEY

\title{
An Assessment of the Ground-Water Resources \\ of Kaho'olawe, Hawai'i \\ Using Transient Electromagnetic and Schlumberger Soundings
}

\section{by}

Jim Kauahikaua

Open-File Report 89-468

This report is preliminary and has not been reviewed for conformity with U.S. Geological Survey editorial standards or with the North American stratigraphic Code. Any use of trade, product, or firm names is for descriptive purposes only and does not imply endorsement by the U.S. Geological Survey. 


\begin{abstract}
Five Schlumberger and 24 transient electromagnetic soundings were successfully obtained on Kaho'olawe, Hawai'i for the purpose of assessing the island's ground-water potential. The soundings were intended to determine the depth to a conductor at or below sea level which is thought to represent seawater-saturated basalts. The most common type of fresh-water occurrence in Hawaii, the fresh-water lens, would be revealed in such soundings as a conductor which is significantly deeper than sea level. The soundings in this study show that the conductor is anomalously deep beneath the central eastern portion of Kaho'olawe. It is impossible to derive a unique interpretation for the geometry and salinity of the fresh-water lens interpreted above the conductor, but it is possible to show that select simple lens geometries would yield a similar pattern of sounding results.
\end{abstract}




\section{Introduction}

"Kaho'olawe is a single shield volcano with a caldera, almost 5 kilometers in diameter, at its present eastern end" (Macdonald and others, 1983). Kaho'olawe (Figure 1) is better known among long-time Hawai'i residents as the "Target Isle" because of the Navy's persistent bombing, artillery, and land assault practice on the island. The island has been a center of controversy because it is close to Maui, a fast-growing residential and tourist center, and because native Hawaiian groups have demanded that the bombing be stopped and the island returned to the Hawaiian public. Recently, the state of Hawai'i has provided limited funds to study erosion control and assess the surface and ground-water resources of the island. This report summarizes the results of geophysical soundings obtained during three trips to the island in 1988 to aid the ground-water assessment of Kaho'olawe.

Electrical geophysical methods are ideal for this type of ground-water assessment because they respond only to the resistivities of earth materials which are largely controlled by degree of weathering, the salinity and degree of saturation by fluids. Because of the significantly lower resistivity of salt water compared to fresh water, these techniques have the potential to discriminate between basalt that is unsaturated or saturated with fresh water and basalt that is saturated with salt water. If we assume that most fresh ground water in Hawai' is in the from of a lens floating on salt water, and that geophysical techniques, while not allowing detection of fresh water directly, can determine how deep below sea level salt water can be found, then geophysical techniques can estimate the thickness of the fresh water lens (Swartz, 1937).

\section{Previous Studies}

Because access to the island is limited by the military, few geophysical studies have been done on Kaho'olawe. The geology and ground-water potential were studied by Stearns (1940). His conclusions on ground water were:

"There are several sites where a drilled well might tap water in the dike complex, but the most promising place at the lowest elevation, is at an altitude of 800 feet in Ahupu Gulch, 1 mile southwest of Moaula cone. A well at this place should encounter the north margin of the southwest rift zone, but the dikes may not be close enough to confine water. A well at an altitude of 1,200 feet half a mile east of this site would penetrate even more certainly the dike complex. The height of the water table at these sites is unknown, but it may not be far above sea level because of small recharge. Resistivity station $A$ indicated a water table only about 1.0 foot above mean sea level not far away."

The results of four resistivity soundings were included in that Bulletin. They were all located on the northern flank of the island and did not indicate any large fresh-water aquifers (Stearns, 1940). A reconnaissance gravity survey (Furumoto, 1965) showed the highest Bouguer anomalies were in the southern half of the island. Because gravity highs often indicate dike zones on other Hawailan islands (Strange and others, 1965), and dike zones often host large fresh-water bodies (Takasaki and Mink, 1985), this data suggested that exploration of the southern portion of the island might be more successful.

\section{Field and Interpretation Procedures}

Five Schlumberger soundings were obtained on the island at the locations shown in Figure 2. 
The data were obtained using a SYSCAL R2 resistivity meter. AB/2 distances ranged from 9.1 to $1524 \mathrm{~m}(30-5000 \mathrm{ft})$ and $\mathrm{MN} / 2$ distances ranged from 1.8 to $61 \mathrm{~m}(6-200 \mathrm{ft})$. Field procedures were identical to those reported in Kauahikaua and Jackson (1988). The data were preliminarily interpreted with an automatic inversion program written by Zohdy and Bisdorf (1989) followed by a detailed inversion as described in Kauahikaua and Jackson (1988) using program MARQDCLAGT on an Hewlett-Packard 9000/320 microcomputer. The computer interpretations are included in Appendix A.

Twenty-four transient electromagnetic soundings were obtained on Kaho'olawe (locations shown in Figure 2) using the SIROTEM II electronic switcher and digital receiver. The SIROTEM box was connected to two square wire loops each $152.4 \mathrm{~m}(500 \mathrm{ft})$ on a side in the coincident offset configuration. In this configuration, the two loops are offset along a diagonal by approximately 6-10 $m$. One loop functions as the transmitter while the other functions as the receiver. The general application of transient electromagnetic techniques to ground-water problems is described by Fitterman and Stewart (1986).

It is necessary to use the offset coincident configuration (displaced loops configuration; Buselli, 1982) in Hawai'i because of the problem of superparamagnetism in the soil (Buselli, 1982). The 4 to 7 Amps of current carried by the transmitter loop is sufficient to temporarily magnetize the soil. Under normal operation, the receiver records the decay of ground currents after the transmitter current is turned off; however, on superparamagnetic soil, the receiver also records voltages induced by the soil becoming demagnetized. Offsetting the receiver from the transmitter reduces the superparamagnetic signal from the soil immediately adjacent to the transmitter wire, but does not significantly reduce the signal from the decaying ground currents. It is impossible to completely remove the superparamagnetic signal, so its effects must always be kept in mind during interpretation of transient electromagnetic soundings in Hawai'i. The superparamagnetic signal is an undesirable artifact that resembles the signal from a deep conductor with the depth to it increasing with loop size. The most straight-forward way of dealing with this problem, besides using the offset-coincident or central-induction configuration, is to determine the apparent conductor depth due to the superparamagnetic signal alone for each loop size used and report it as a maximum penetration depth. This is done in practice by obtaining SIROTEM soundings over a known, highly-resistive section with different sized loops in a coincident offset configuration. The obtained

data should be all superparamagnetic signal which may be inverted as real sounding data. For the $152.4 \mathrm{~m}$ loops used on Kaho'olawe, the greatest penetration depth is about $700 \mathrm{~m}$.

The SIROTEM data were interpreted for the best-fitting layered earth model by computer program NLSTCO (Anderson, 1982) running on a VAX 11/750 located at the Hawailan Volcano Observatory. The one-dimensional, horizontally-layered interpretations are shown in Appendix B and are summarized in Table I. The apparent-resistivity-versus-time data plots each had a maximum apparent resistivity at a time midway within the 0.8 to $164 \mathrm{~ms}$ measurement range. In seven of the sounding plots, the apparent resistivities increased too steeply at early times to be fitted by any horizontally-layered earth model. Most of these soundings were located along a north-south line shown by asterisks in Figure 4. These data could be fit adequately by using only the data near the maximum and at later times. Data from soundings to the west were fit well with a layered-earth model. The value of the apparent resistivity maximum was lower in all soundings to the east of this line.

The effect of the non-zero transmitter turn-off time was not taken into account for the SIROTEM data. Fitterman and Anderson (1987) state that this will give first-layer resistivities which are too small. Because the object of this study was not to determine accurate resistivities of the materials involved, but only to determine their geometry, this effect is not significant. 
SIROTEM soundings were located at each of the four Schlumberger sounding locations in order to compare interpretations. Figure 3 shows the resuits of the two types of soundings at the four coincident sounding locations. In all four comparisons, the SIROTEM sounding data resolves only one layer at the surface over a thick, more resistive layer whereas the Schlumberger sounding data resolves two or three layers over the thick, resistive layer. SIROTEM's poor resolution at shailow depth is a consequence of the range of measurement times. Had that range extended into earlier times, shallow resolution would have been enhanced. Figure $3 a$ and $3 b$ show pairs of sounding interpretations that agree reasonably well as to the estimated depth to basement conductor. The interpretation for Schlumberger sounding \#01 in Figure $3 \mathrm{c}$ did not resoive a basement conductor to a depth of at least $900 \mathrm{~m}$ whereas the interpretation for SIROTEM sounding \#11 at the same site required a basement conductor at about $600-700 \mathrm{~m}$ below the surface. Note that this is the same depth range that we expect the SIROTEM data to be contaminated by superparamagnetic responses from the soil. Therefore, we may conclude that the SIROTEM interpretation is not valid below about $600 \mathrm{~m}$ from the surface and that, to that depth, both SIROTEM and Schlumberger sounding interpretations did not require a basement conductor.

Figure 3d compares SIROTEM sounding \#16 and Schlumberger sounding \#03 in the southern end of the island. The Schlumberger data estimate the basement conductor to be at least $200 \mathrm{~m}$ deeper than the SIROTEM data. The reasons for this large a discrepancy are not known although it must be kept in mind that the Schiumberger interpretation suffers from equivalence in determining the resistivity and thickness of the last layer above the basement conductor. That is, if the resistivity of that layer is decreased, the depth to the basement conductor will increase without significantly changing the goodness-of-fit between the theoretical and observed curves. SIROTEM data interpretations do not suffer from that type of equivalence therefore depth-to-conductor estimates from SIROTEM data are probably more reliable than those from Schlumberger data.

\section{Results}

Both types of soundings show that the general vertical structure of Kaho'olawe is made up of three zones. The surface zone has one to three layers of low resistivity ( 8 to $30 \mathrm{ohm}-\mathrm{m}$ ) having a total thickness of 10 to $80 \mathrm{~m}$. This zone probabiy represents the effects of weathering; its low resistivity reflects the presence of clays and some amount of fluid. The weathered zone is thickest near Lua Makika on the eastern end of the island (Figure 4). In detail, the weathered zone appears to be constructed of at least two layers with the surface layer being about twice as resistive as the layer immediately below. The resolution is not always sufficient to resolve these layers with SIROTEM data. The Schlumberger soundings were able to resolve at least two layers in every sounding.

The second zone has the highest resistivities (greater than $38 \mathrm{ohm}-\mathrm{m}$ ) and probably represents relatively unweathered basalts that are either unsaturated or saturated with fresh water. Although many of the resistivity values determined for this layer from SIROTEM measurements are high, it is the most poorly defined parameter of the section. Schiumberger soundings have better definition of this parameter and the determined resistivity values for this layer range from 38 to $170 \mathrm{ohm}-\mathrm{m}$. SIROTEM-determinedvalues much greater than $200 \mathrm{ohm}-\mathrm{m}$ are probably not well resolved and shouid be disregarded. Compared to resistivity values found for similar basalts on other Hawailan islands (see, for example, Mattice, 1981; Kauahikaua and Jackson, 1988), the Kaho'olawe values are unusually low. The values are lowest near Lua Makika (Figure 5). The low resistivities likely are the result of some degree of alteration that would form clay minerals and/or zeolites in pores and vesicles. Lua Makika is within the Kaho'olawe caldera (Stearns, 1940) and may have been the site of later hydrothermal activity and resultant mineral alteration (Fodor and others, 1987; discovery of alunite by Hoover and others, 1982). 
The deepest zone has very low resistivities which average about $4 \mathrm{ohm}-\mathrm{m}$. This zone is also sometimes composed of two layers with the shallower layer being of low ( $<4 \mathrm{ohm}-\mathrm{m})$ resistivity in some soundings and of an intermediate resistivity (9.2 to $60 \mathrm{ohm}-\mathrm{m}$ ) in others. The layers whose resistivities are about $4 \mathrm{ohm}-\mathrm{m}$ or lower represent salt-water saturated basalts. The intermediate resistivities may represent fresh water and/or a transition zone with salinities progressively varying from fresh to seawater. Figure 6 is a map of Kaho'olawe showing the depth below sea level of this basement conductor computed as the difference between the depth to the top of the layer whose resistivity is $7.5 \mathrm{ohm}-\mathrm{m}$ or lower and the elevation. If an intermediate resistivity layer occurs between this layer and the higher unsaturated basalt above, then the depth is computed for the midpoint of the intermediate resistivity layer. The largest depths occur near Lua Makika. The few negative estimates (indicating surface of conductive basement above sea level; see 'Dsw' column in table I) demonstrate the error of such determinations. It is worth noting that, at least near SIROTEM sounding 8 , the presence of disturbing factors such as communication wires over the ground surface may have contributed to the interpretational error.

\section{Significance of Results for Ground Water on Kaho'olawe}

The discovery that conductive material, probably representing seawater-saturated basalts, is absent to $100-150 \mathrm{~m}$ below sea level beneath a portion of Kaho'olawe is anomalous. If brackish to saline water existed everywhere at sea level then the geophysical interpretations should have shown a conductor everywhere whose upper surface was very near sea level. Even though this study shows that this is not the case, there are several reasons why expected seawater-saturated basalt resistivities may not have been detected in this zone.

The most likely non-hydrologic model that would fit this data is a model with significantly lower porosity within the anomalous zone than the rocks outside. The lower porosity would be sufficient to reduce the amount of conductive seawater saturating the basalts thereby increasing the bulk resistivity. If we assume that $4 \mathrm{ohm}-\mathrm{m}$ represents seawater-saturated basalts with a porosity of about $30 \%$, then the porosity would have to be reduced to about $5 \%$ to raise the resistivity to 55 ohm-m (using Archie's law for Hawailan basalts saturated with 18 ppt salinity fluid; Rai and Manghnani, 1981). Possible geological models include a thick zone of dense, ponded lavas, lavas with vesicles filled by alteration minerals within the caldera, or lavas whose bulk porosity has been reduced by repeated dike intrusion.

The most likely hydrologic model is a fresh-water lens floating on seawater or a dike-impounded fresh-water body. From a geophysical point of view, these two models differ only in geometry. A fresh-water lens would be thinner at the edges becoming thicker towards its center. A dike-impounded ground-water body, on the other hand, would have nearly vertical boundaries.

The geophysical data are insufficient to differentiate between these models. Comparison with synthetic SIROTEM soundings over three-dimensional resistivity models (Figure 7; Newman and others, 1987) suggest that any of the non-hydrologic or hydrologic models would fit the data equally well. Further geophysical or geological data might offer some help. Detailed gravity profiles might indicate the presence of dense lavas and/or intrusive or dike zones. Detailed studies of shorelines at either end of the anomalous zone might reveal fresh-water seeps. But, in the end, no additional set of data can show that the anomaly described in this report is not due to some type of fresh-water body. Therefore, drilling is now recommended somewhere within the anomaly preferably near Lua Makika. 


\section{Appendix A: Schlumberger Sounding Interpretation Results}

The Schlumberger sounding data were interpreted using program MARQDCLAGT running on a Hewlett-Packard 9000/320 microcomputer as described in Kauahikaua and Jackson (1988). This program is based on one written by Anderson (1979). For each sounding, the interpretation is described as a series of resistivities and layer thicknesses. The three columns of figures beneath either heading of "RESISTIVITY" or "THICKNESS" represent the lower bound of the estimate, the estimate, and the upper bound of the estimate for each labelled parameter. "DEPTH" is the depth of the layer's upper surface from the ground surface and "ELEV" is the elevation of the layer's upper surface relative to sea level. Each data set are plotted along with the best-fitting model. 
DCLAG: ******* END

COORDINATES: 00

ELEVATION : 445 METER

AZIMUTH : NSOE

\begin{tabular}{|c|c|c|c|c|c|c|c|}
\hline \multicolumn{3}{|c|}{ RESISTIVITY } & \multicolumn{3}{|c|}{ THICKNESS } & DEPTH & ELEV \\
\hline$* * * * * * * * *$ & $15.0 *$ & $* * * * *$ & .6 & .7 & .9 & 0.0 & 445.0 \\
\hline ********* & $47.0 \times$ & ***** & 2.2 & 2.8 & 3.5 & .7 & 444.3 \\
\hline $\begin{array}{r}15.6 \\
53.6\end{array}$ & $\begin{array}{l}17.3 \\
58.2\end{array}$ & $\begin{array}{l}19.3 \\
63.2\end{array}$ & 35.1 & $\cdots-44.8$ & 57.2 & $\begin{array}{r}3.5 \\
48.3\end{array}$ & $\begin{array}{l}441.5 \\
396.7\end{array}$ \\
\hline
\end{tabular}

Kaho'olawe 1 W lip Lua Makika 13/4/88

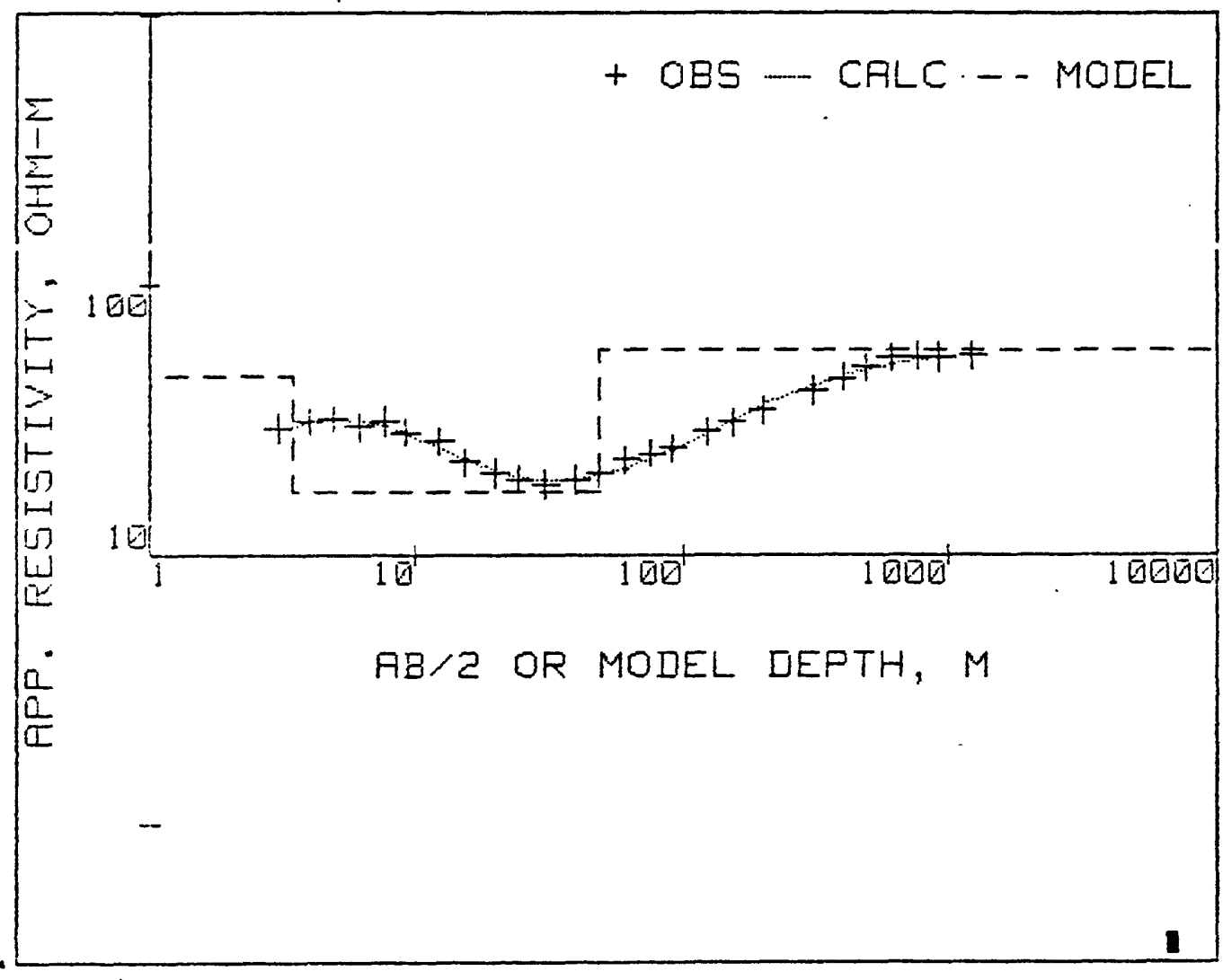




\begin{tabular}{rrr}
\multicolumn{3}{c}{ RESISTIUITY } \\
\hline ******* & $15.0 * * * * * * *$ \\
8.1 & 45.1 & 253.1 \\
14.6 & 17.9 & 21.8 \\
55.4 & 60.3 & 65.7
\end{tabular}

\begin{tabular}{rrr} 
& THICKNESS \\
\hline .4 & 1.1 & 3.5 \\
.2 & 3.0 & 48.5 \\
27.2 & 41.5 & 63.2
\end{tabular}

$\begin{array}{rr}\text { DEPTH } & \text { ELEV } \\ 0.0 & 445.0 \\ 1.1 & 443.9 \\ 4.2 & 440.8 \\ 45.6 & 399.4\end{array}$

Kaho' olawe02 W Iip Lua Makika 14/04/88

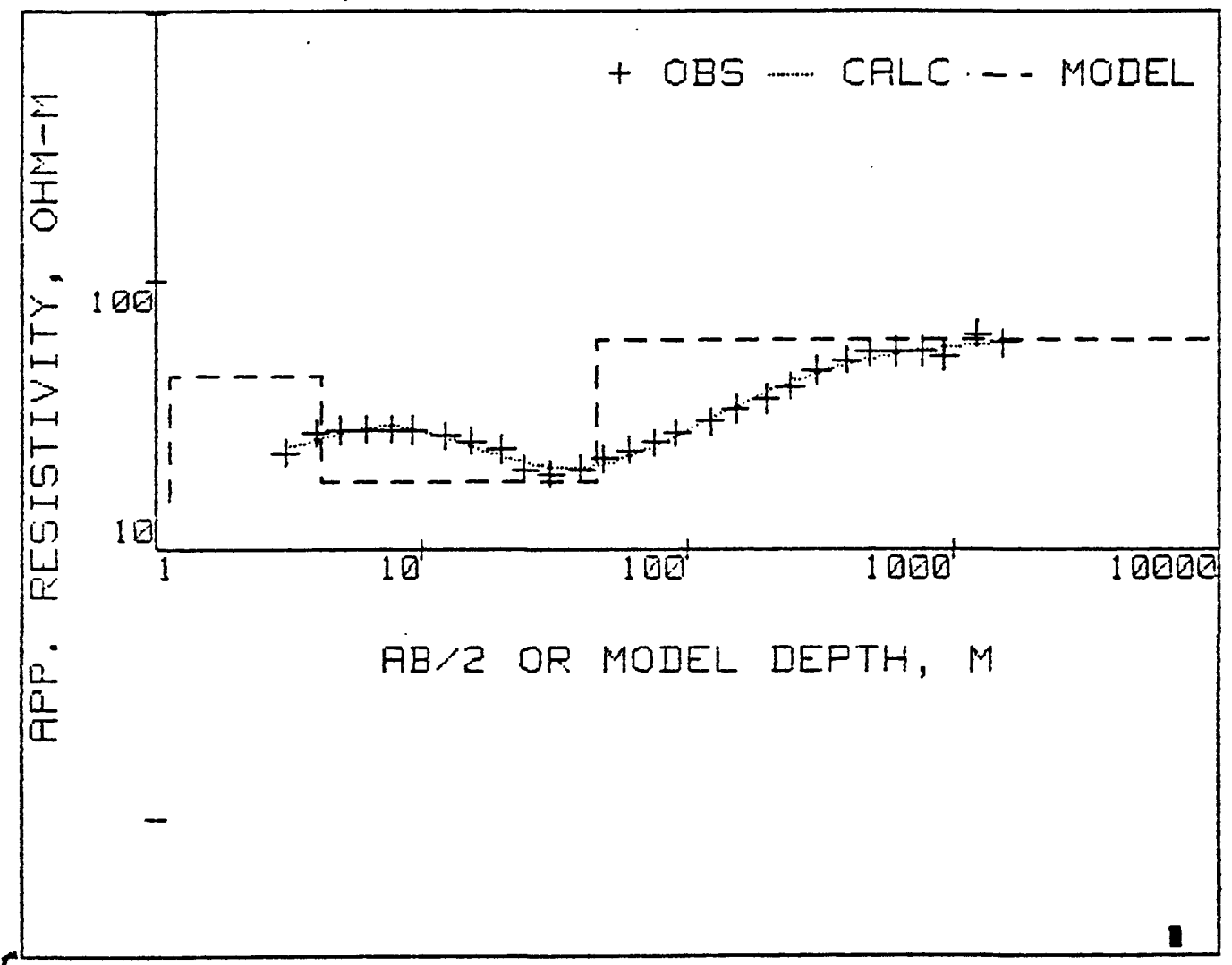


DCLAG: ******* END

COORDINATES: 00

ELEVATION : 235 METER

AZIMUTH : WOSN

\begin{tabular}{|c|c|c|c|c|c|c|c|}
\hline \multicolumn{3}{|c|}{ RESISTIUITY } & \multicolumn{3}{|c|}{ THICKNESS } & \multirow{2}{*}{$\begin{array}{r}\text { DEPTH } \\
0.0\end{array}$} & \multirow{2}{*}{ ELEV } \\
\hline $\begin{array}{r}21.4 \\
5.2\end{array}$ & $\begin{array}{r}43.0 \\
7.4\end{array}$ & $\begin{array}{l}86.5 \\
10.6\end{array}$ & $\begin{array}{r}1.2 \\
14.0\end{array}$ & $\begin{array}{r}2.1 \\
26.0\end{array}$ & $\begin{array}{r}3.5 \\
48.5\end{array}$ & & \\
\hline 31.0 & 99.7 & 320.4 & 68.3 & 447.6 & 2933.4 & 28.1 & 206.9 \\
\hline ******** & 4.0 & $* * * * *$ & & & & 475.7 & -240.7 \\
\hline
\end{tabular}

Kaho'olawe 03 hardpan SE end 14/04/88

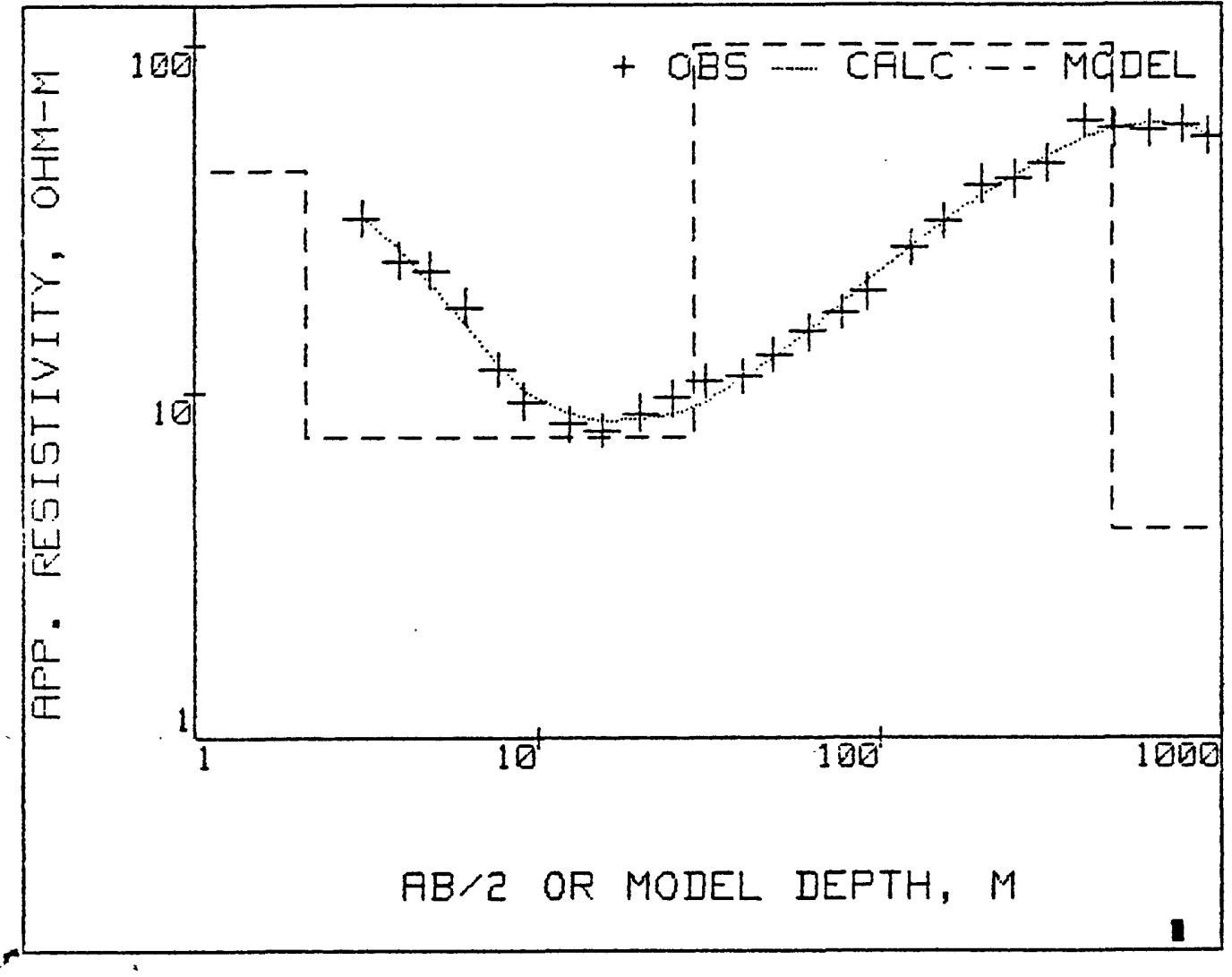


DCLAG: ******* END

COORDINATES: 00

ELEUATION : 320 METER

AZIMUTH : NTOE

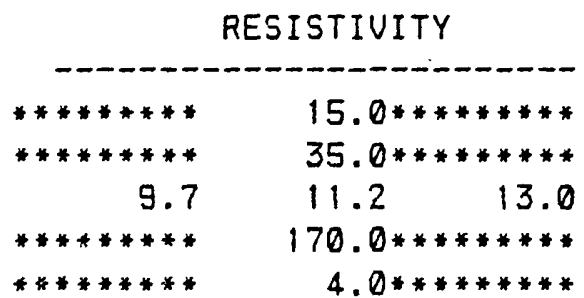

\begin{tabular}{rrr}
\multicolumn{3}{c}{ THICKNESS } \\
.4 & .6 & 1.0 \\
3.0 & 3.7 & 4.7 \\
45.1 & 55.4 & 68.1 \\
207.3 & 242.3 & 283.1
\end{tabular}

DEPTH ELEV

.0

4.7

0.0320 .0

$.6 \quad 319.4$

$4.4 \quad 315.6$

$59.8 \quad 260.2$

$302.1 \quad 17.9$

Kaho'olawe04 Pu'u Moiwi 15/04/88

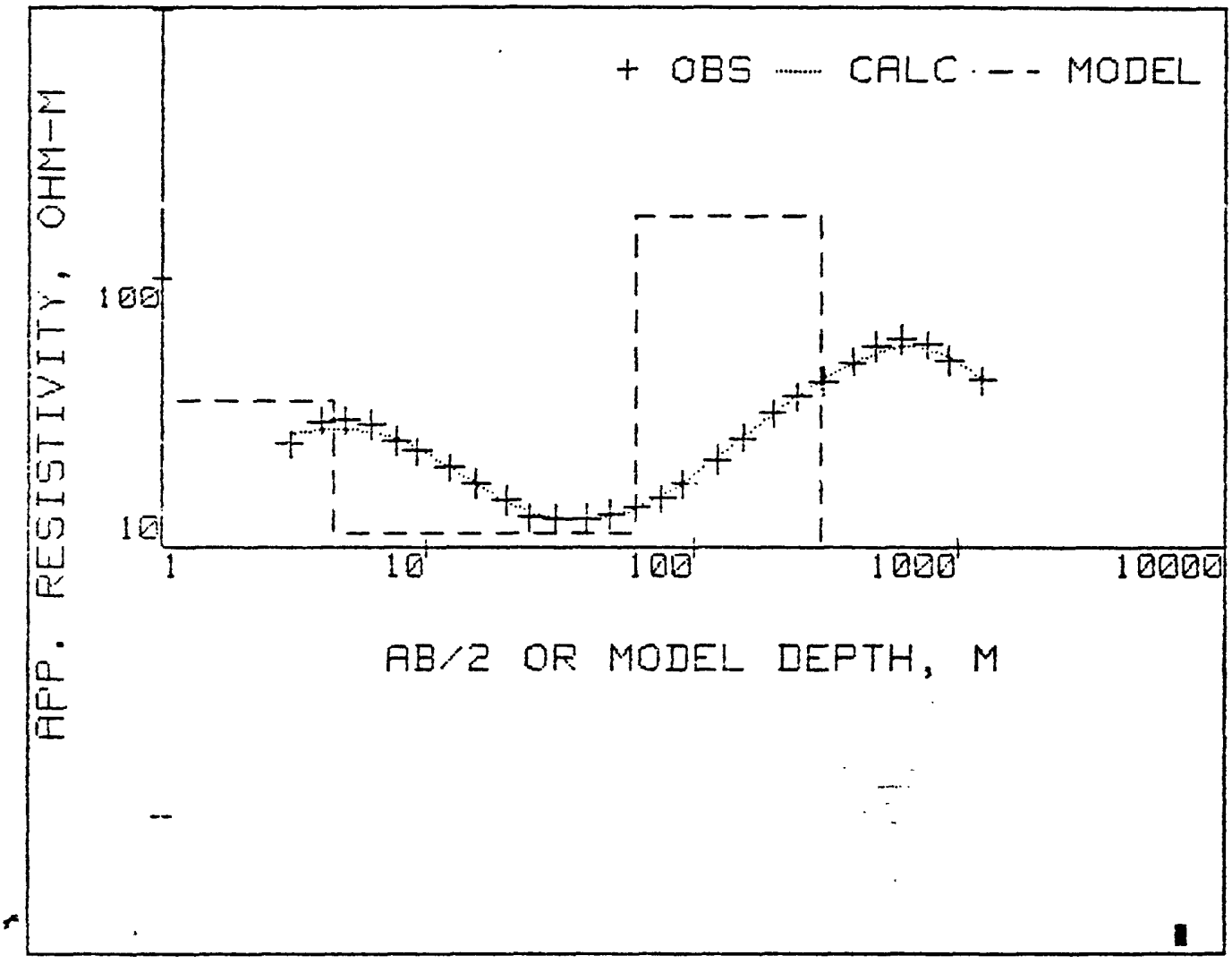


OCLAG: ******* END

COORDINATES: 00

ELEVATION : 200 METES

AZIMUTH : $535 W$

\begin{tabular}{|c|c|c|c|c|c|c|c|}
\hline \multicolumn{3}{|c|}{ RESISTIUITY } & \multicolumn{3}{|c|}{ THICKNESS } & DEPTH & ELEV \\
\hline $\begin{array}{r}26.9 \\
2.4\end{array}$ & $\begin{array}{r}29.7 \\
9.6\end{array}$ & $\begin{array}{l}32.8 \\
37.5\end{array}$ & $\begin{array}{l}5.6 \\
5.2\end{array}$ & $\begin{array}{l}11.0 \\
23.9\end{array}$ & $\begin{array}{r}21.4 \\
110.6\end{array}$ & $\begin{array}{r}0.0 \\
11.0\end{array}$ & $\begin{array}{l}200.0 \\
189.0\end{array}$ \\
\hline$* * * * * * * *$ & 170.0 & $* * * * *$ & $24 i .9$ & 274.9 & 312.3 & 34.9 & 165.1 \\
\hline ********* & 4.0 & $* * * * *$ & & & & 309.7 & -109.7 \\
\hline
\end{tabular}

Kaho'olawe05 Lua Keaualalo 15/04/88

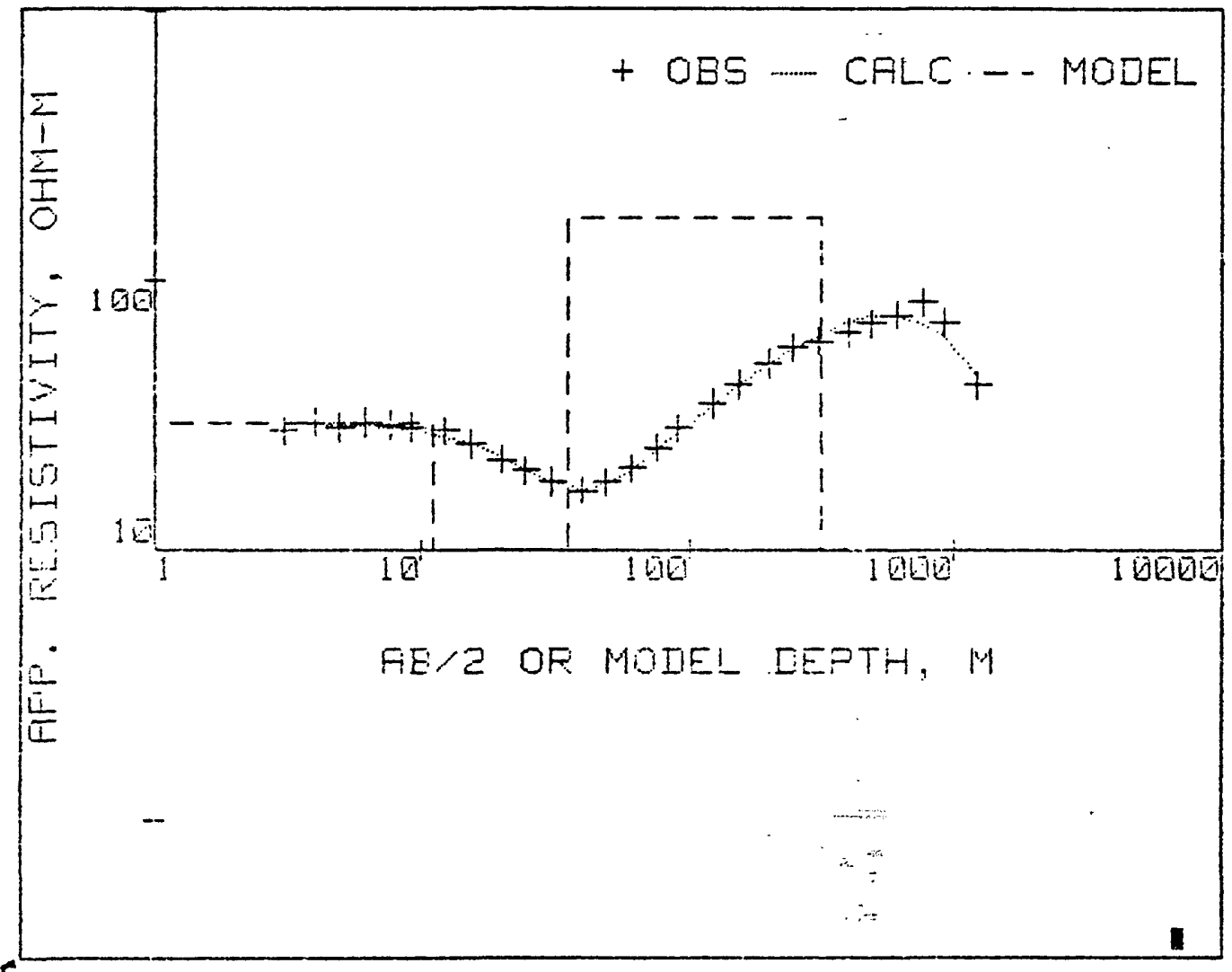




\section{Appendix B: SIROTEM Sounding Interpretation Results}

The SIROTEM interpretations are listed as output from VAX FORTRAN program NLSTCO (Anderson, 1982). Resistivities in ohm-m, are listed beneath the "RESISTIVITY" heading and depth below surface to the bottom of each layer in meters is listed beneath the "LAYER DEPTH" heading.

Each data set is plotted as apparent resistivity versus measurement time using the all-time conversion from measured volts (Raab and Frischknecht,1983). The plots are all base $10 \log -\mathrm{log}$ types with the leftmost vertical line representing $1 \mathrm{msec}$ and the horizontal base representing 10 ohm-m. Data are plotted as a solid line and the best-fitting model is plotted as a dashed line. 


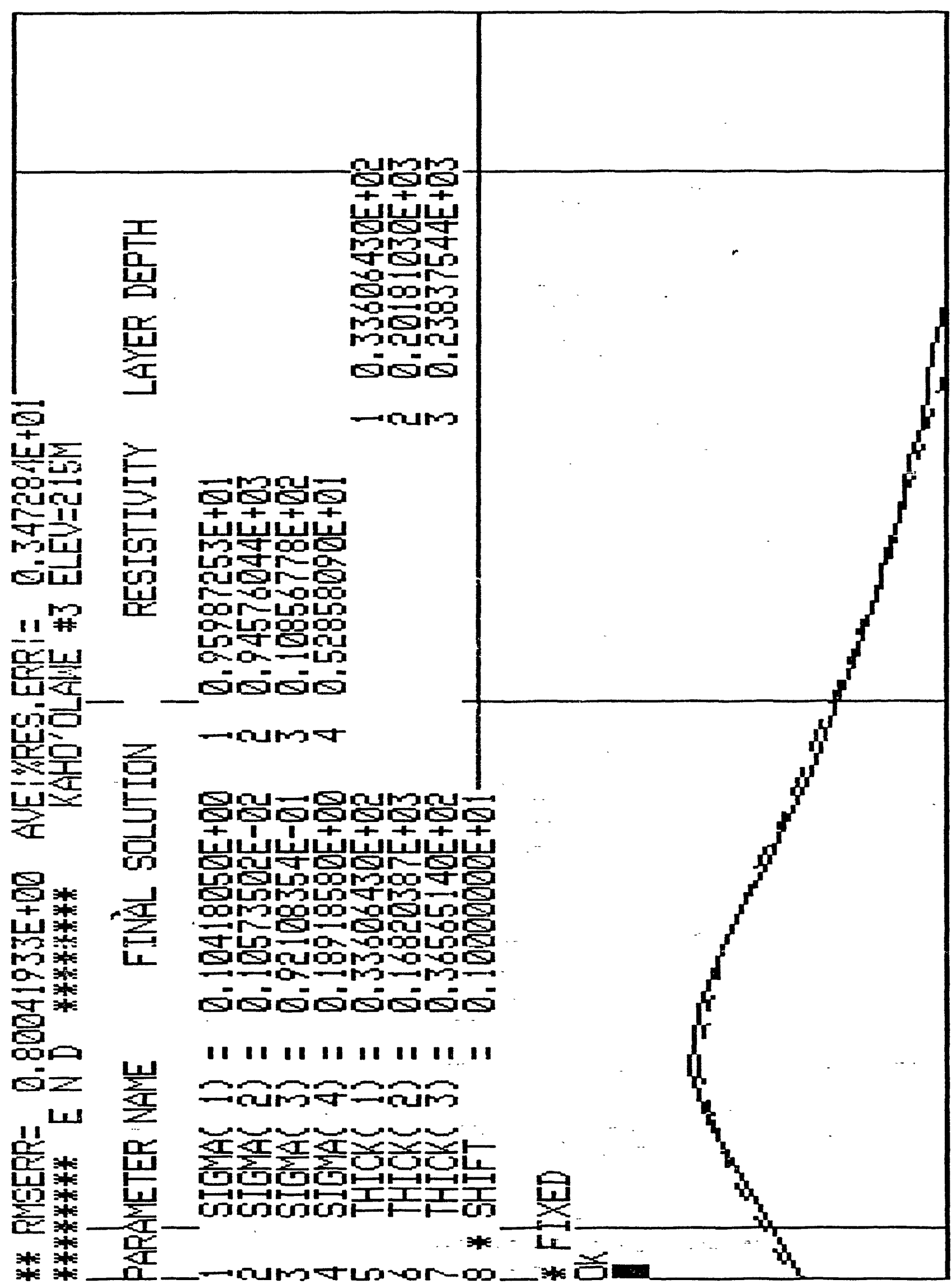

8.2 


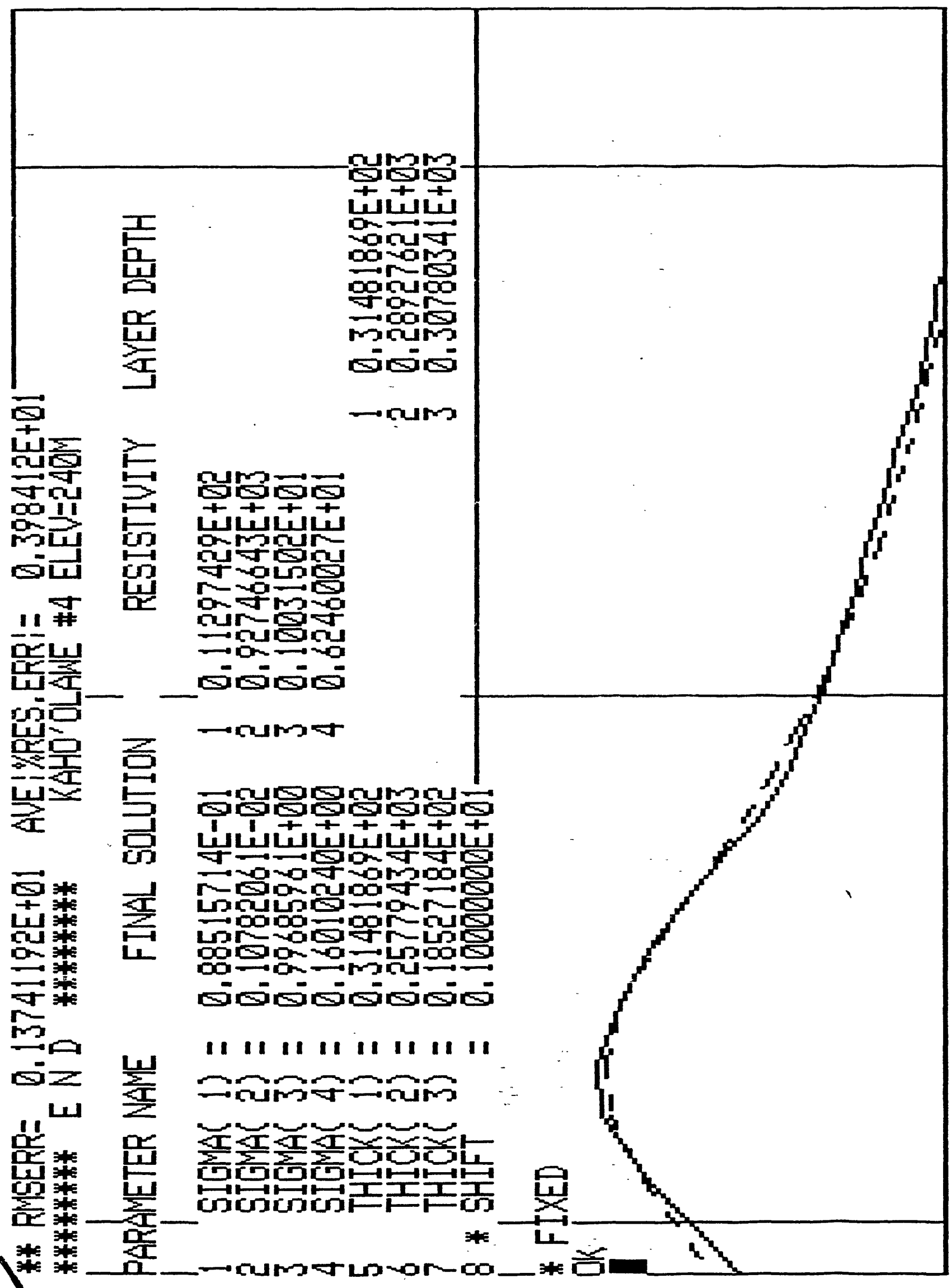




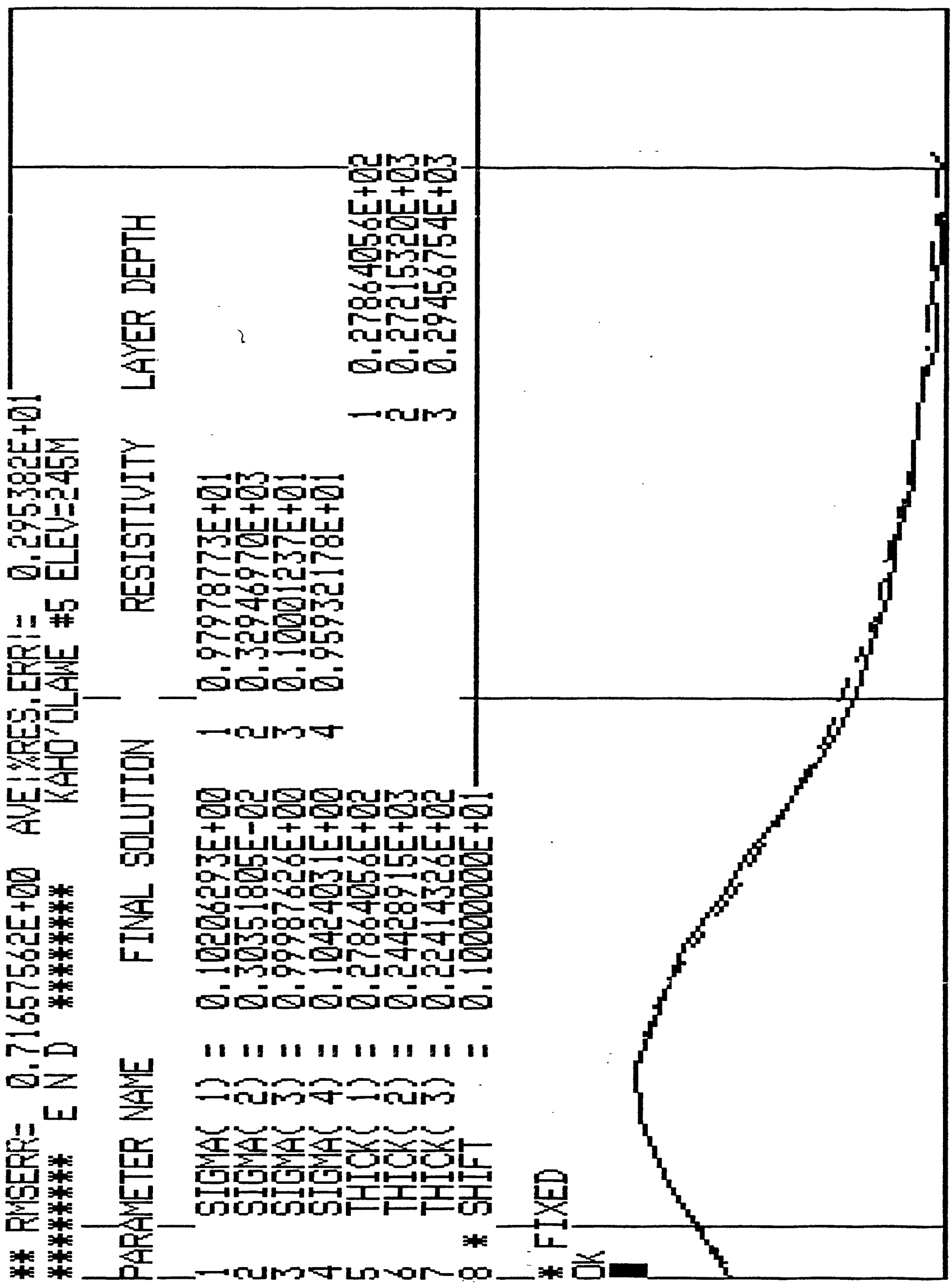




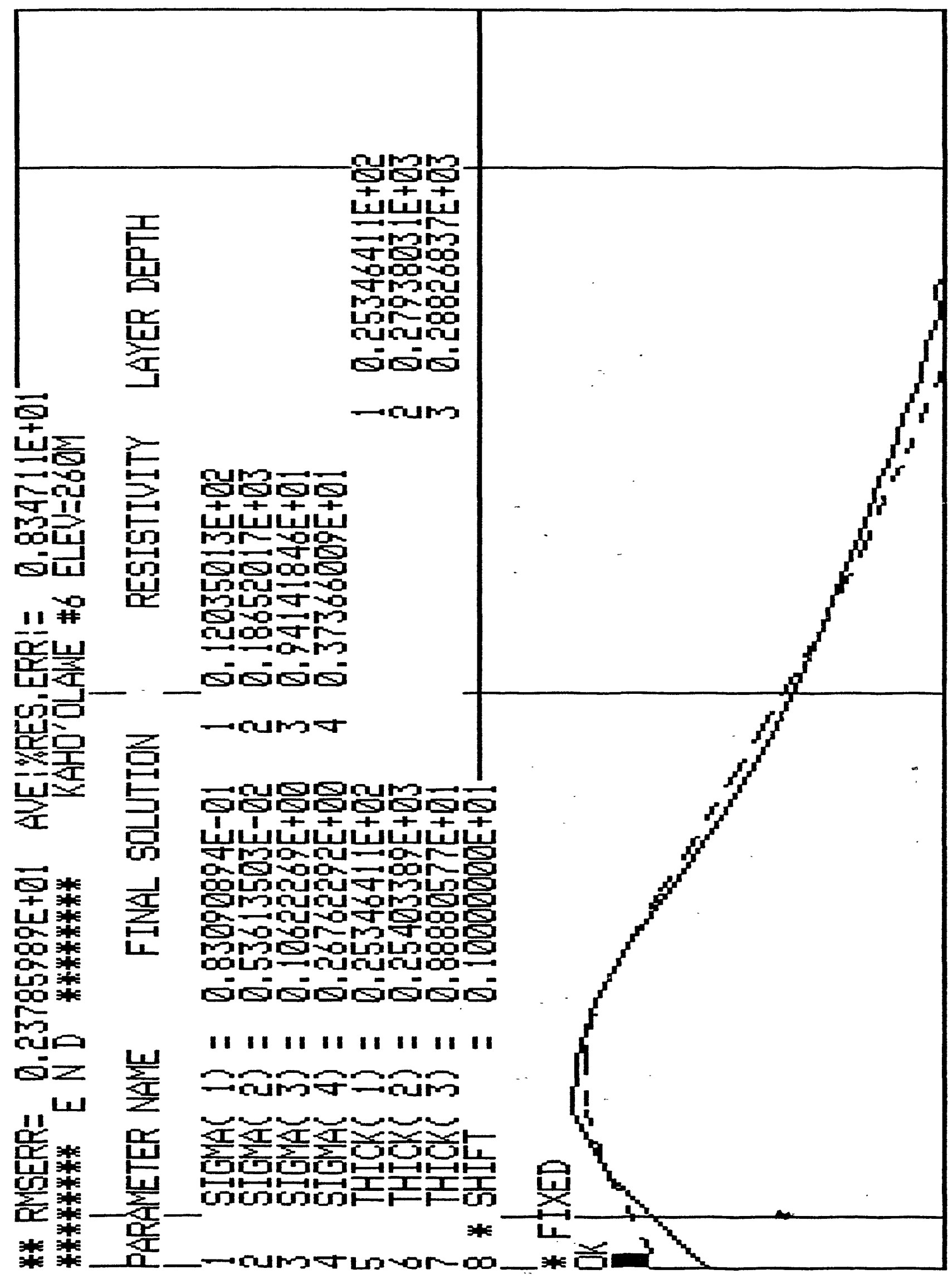




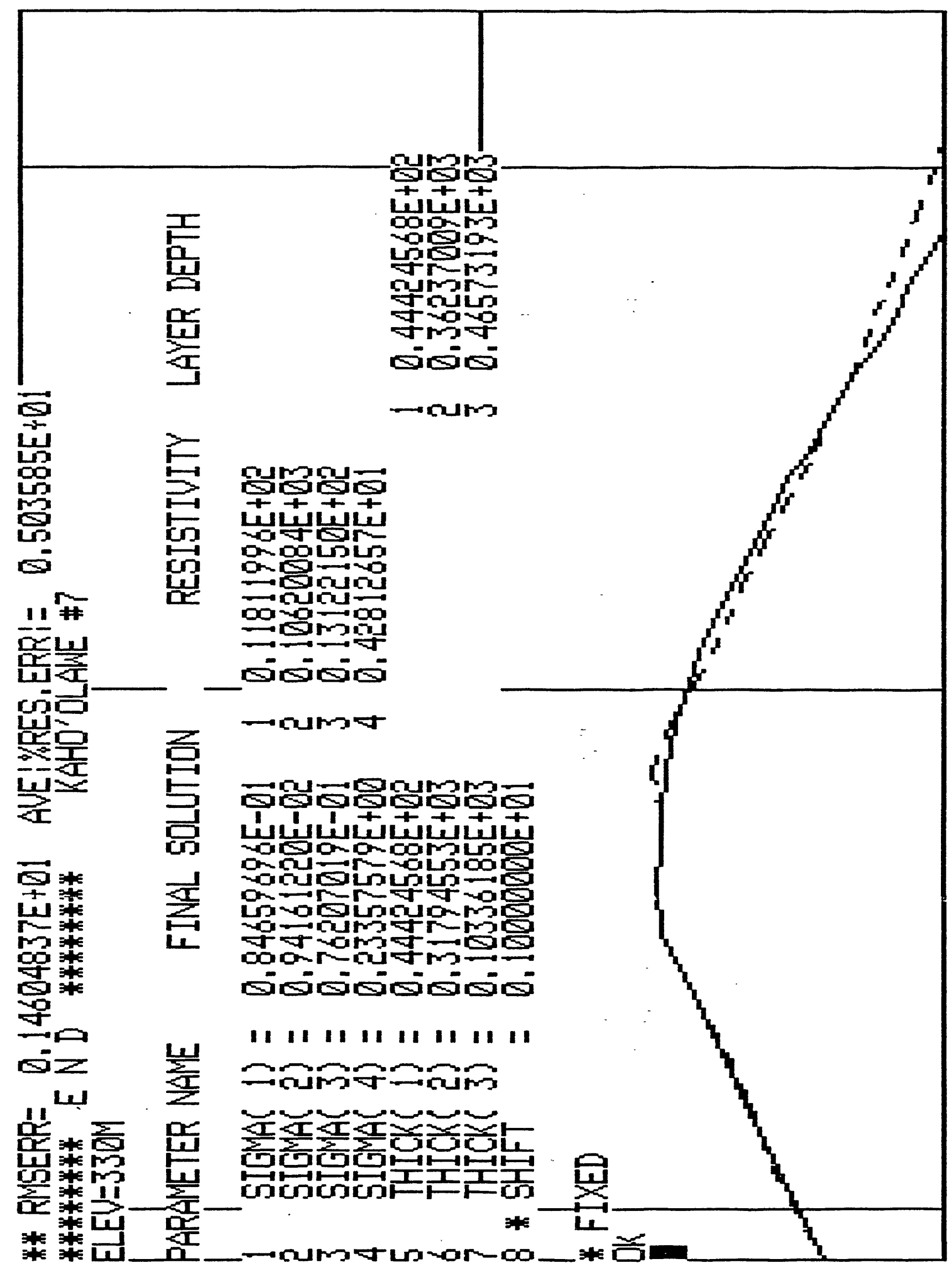




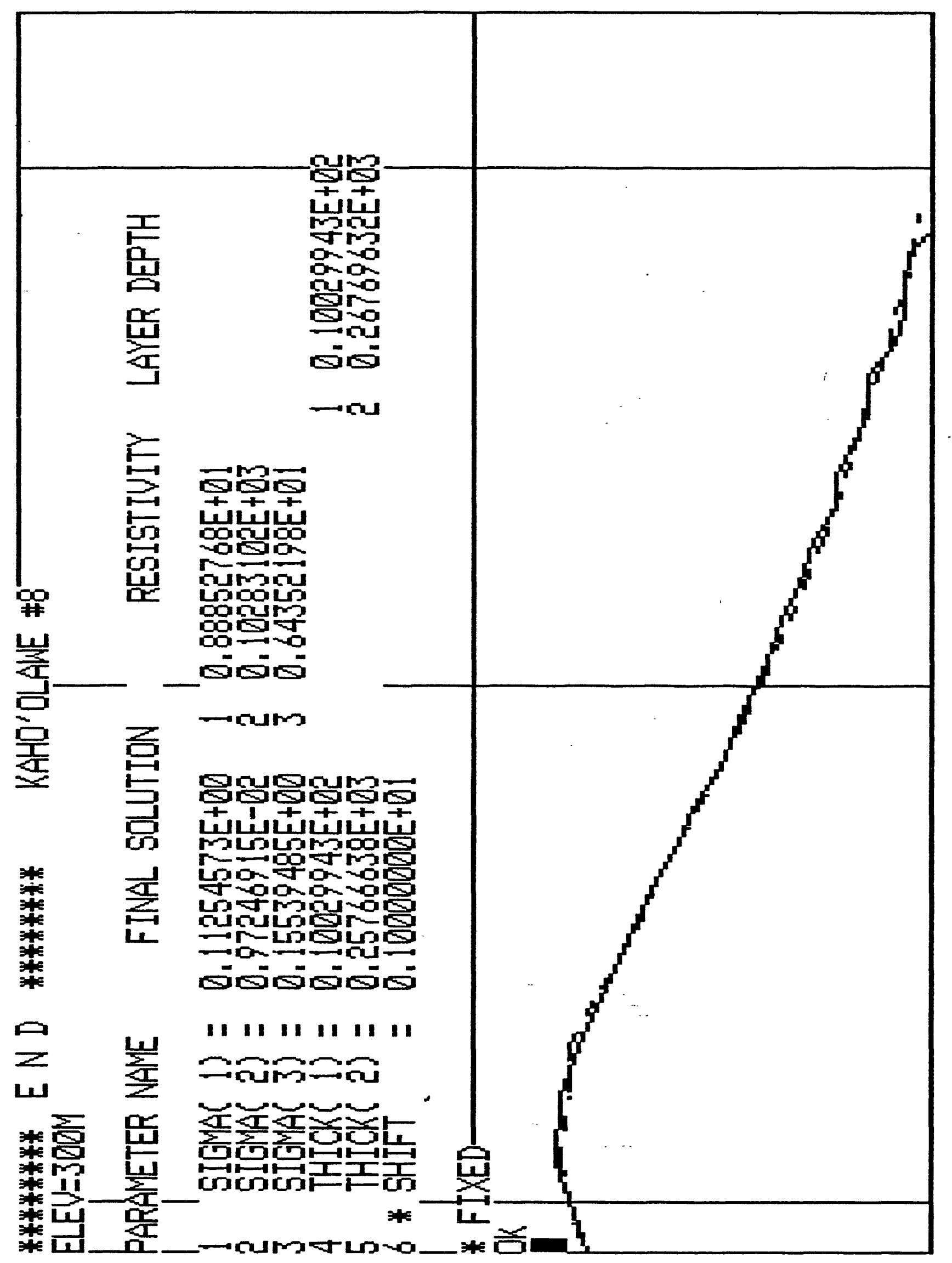

8.7 


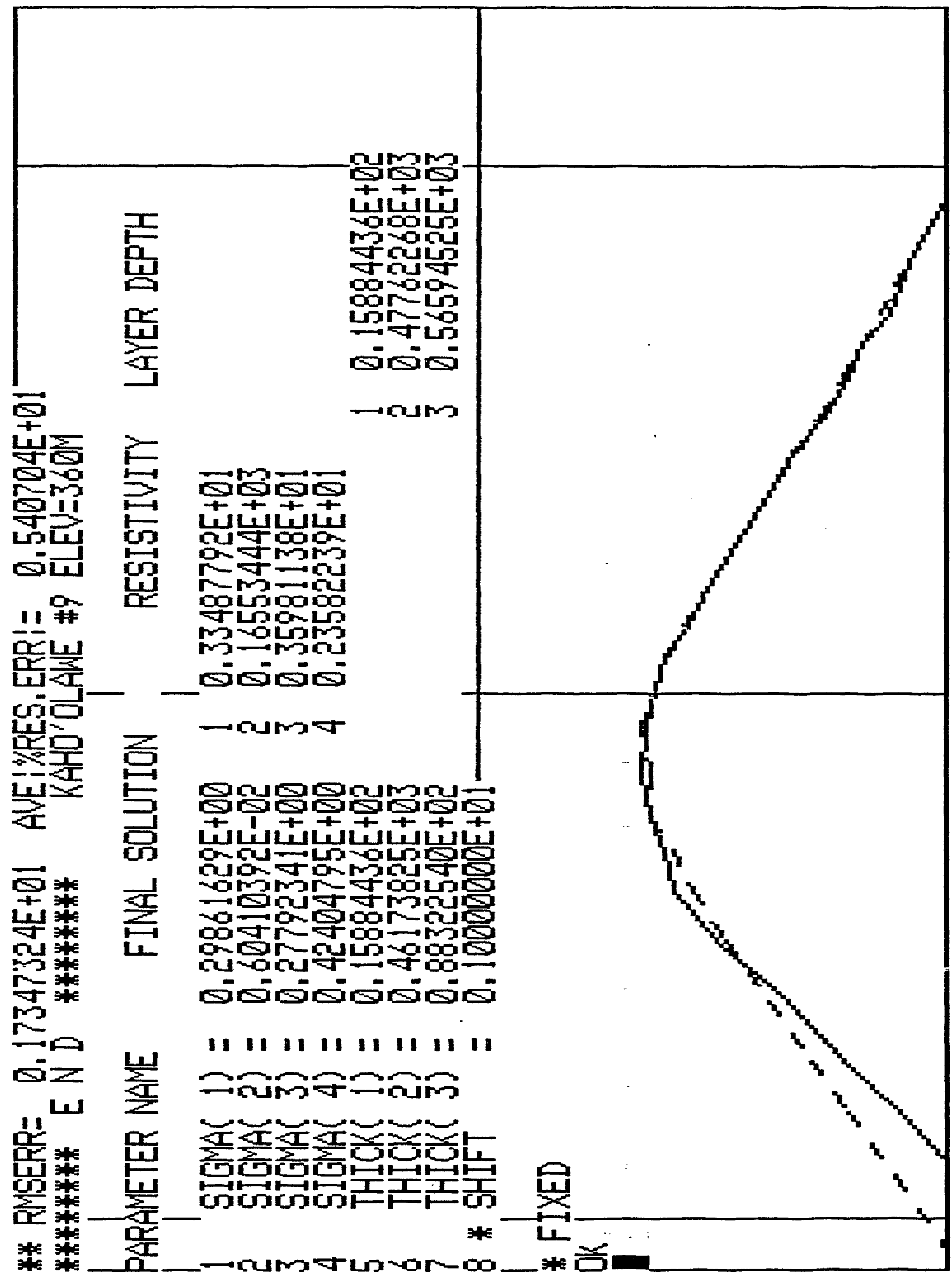




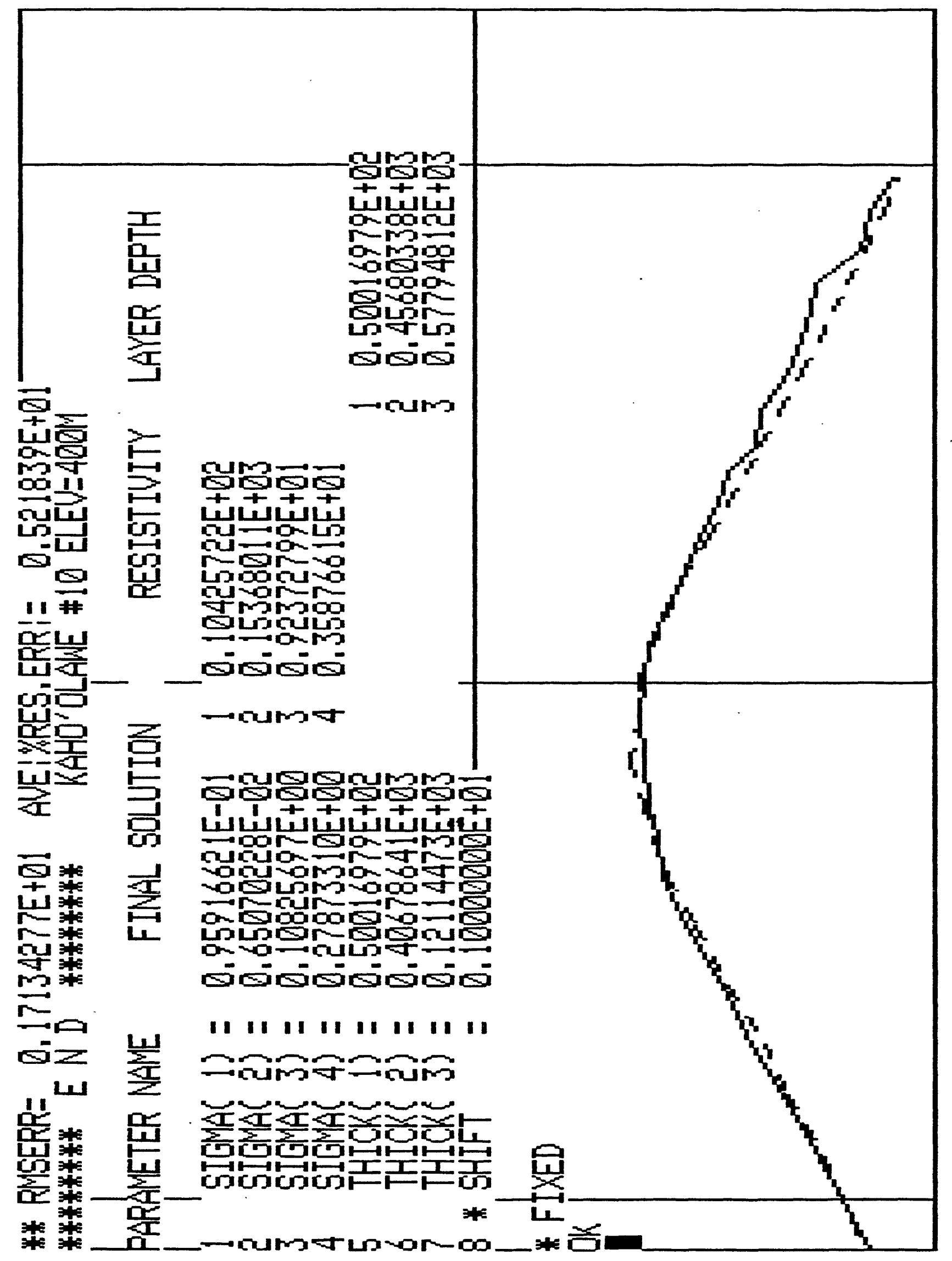

8.9 


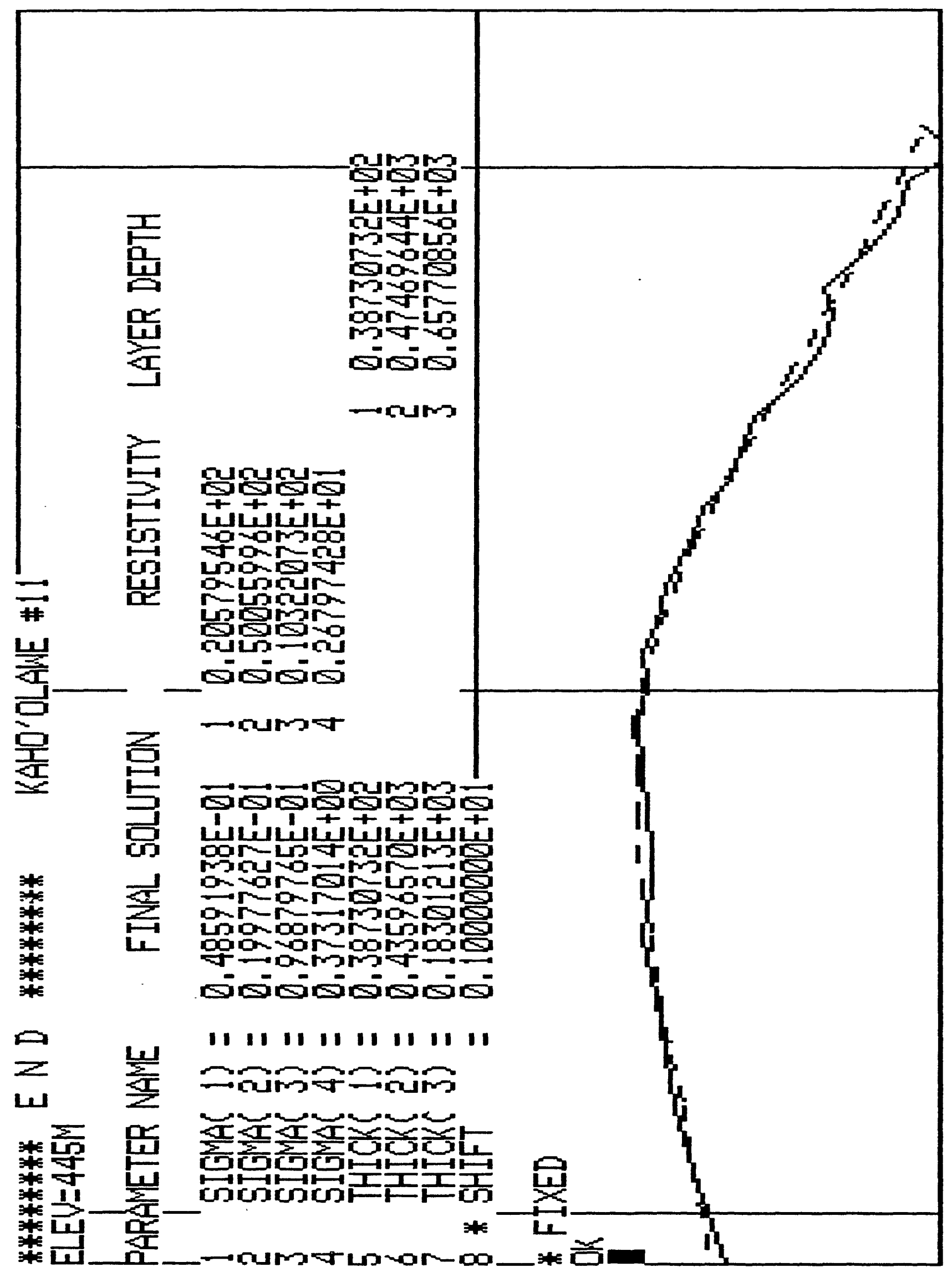




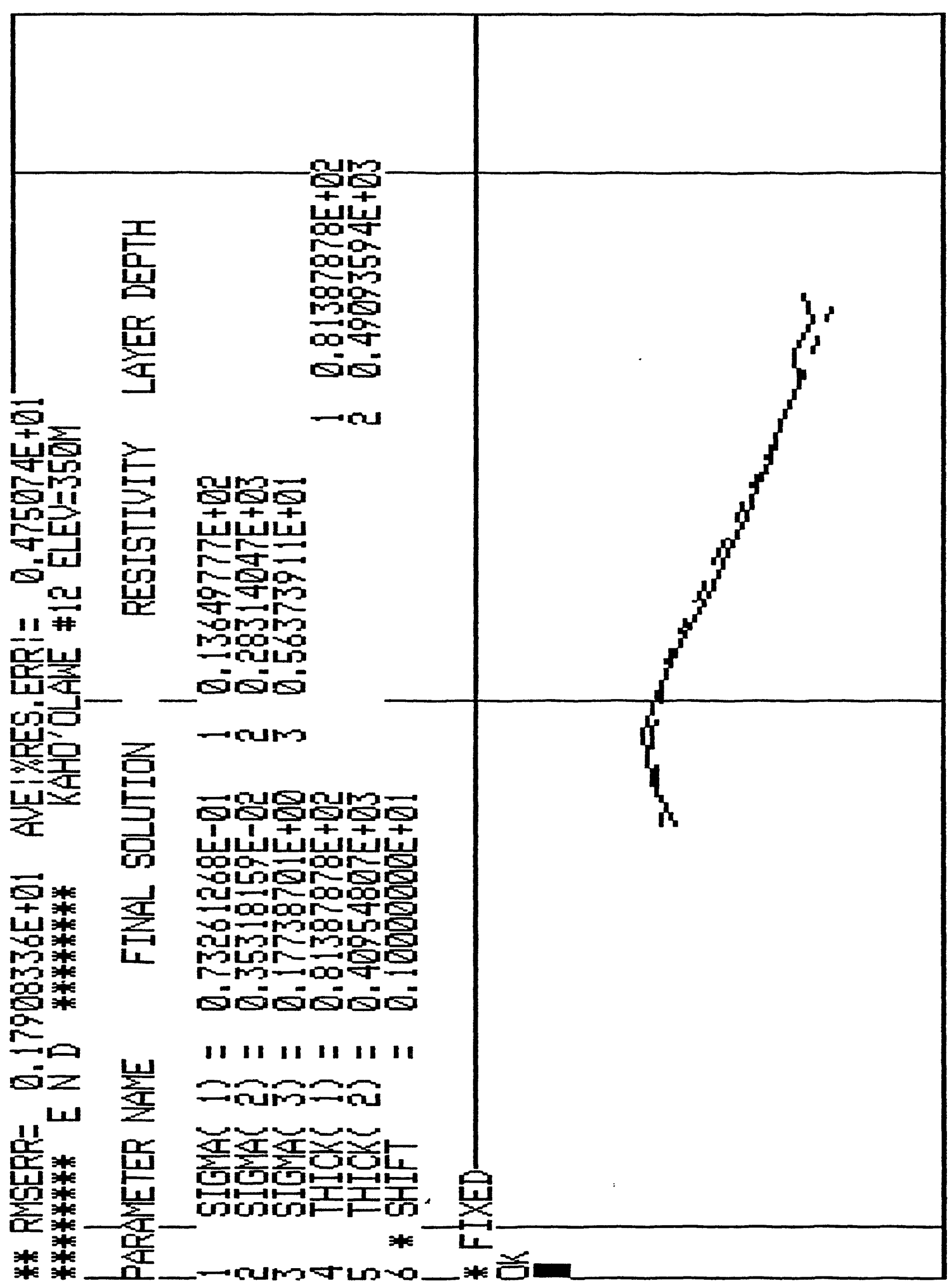




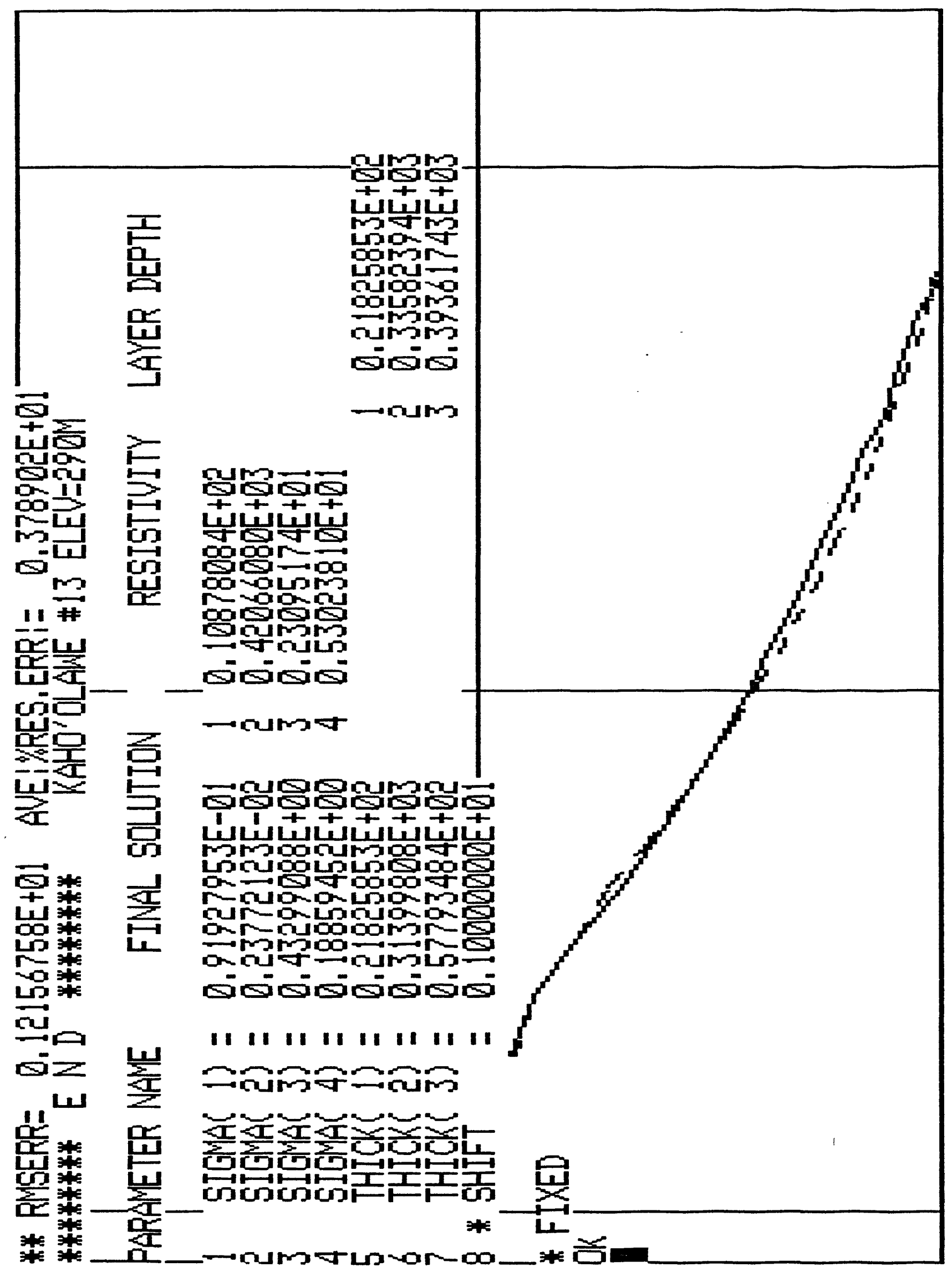




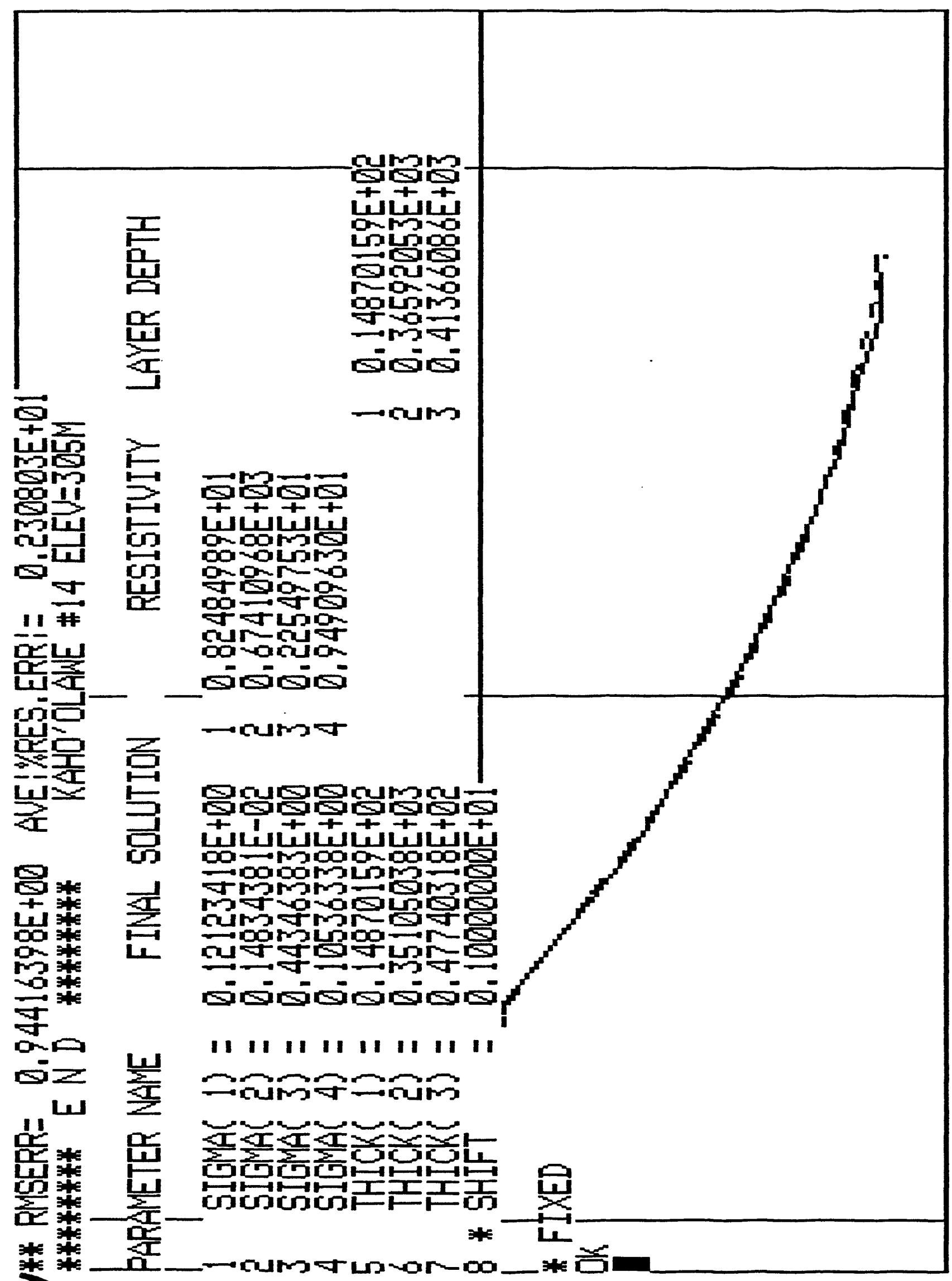




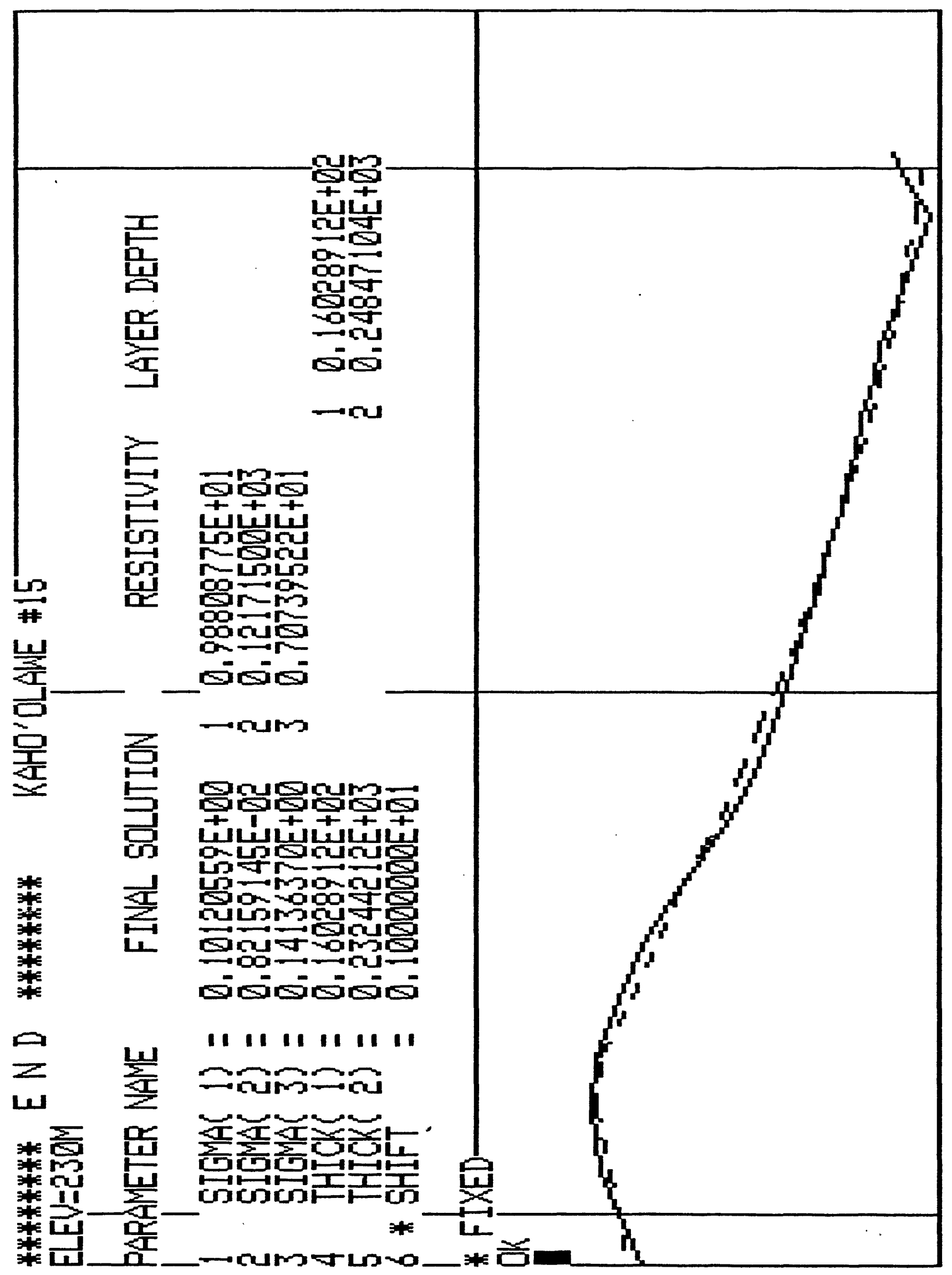




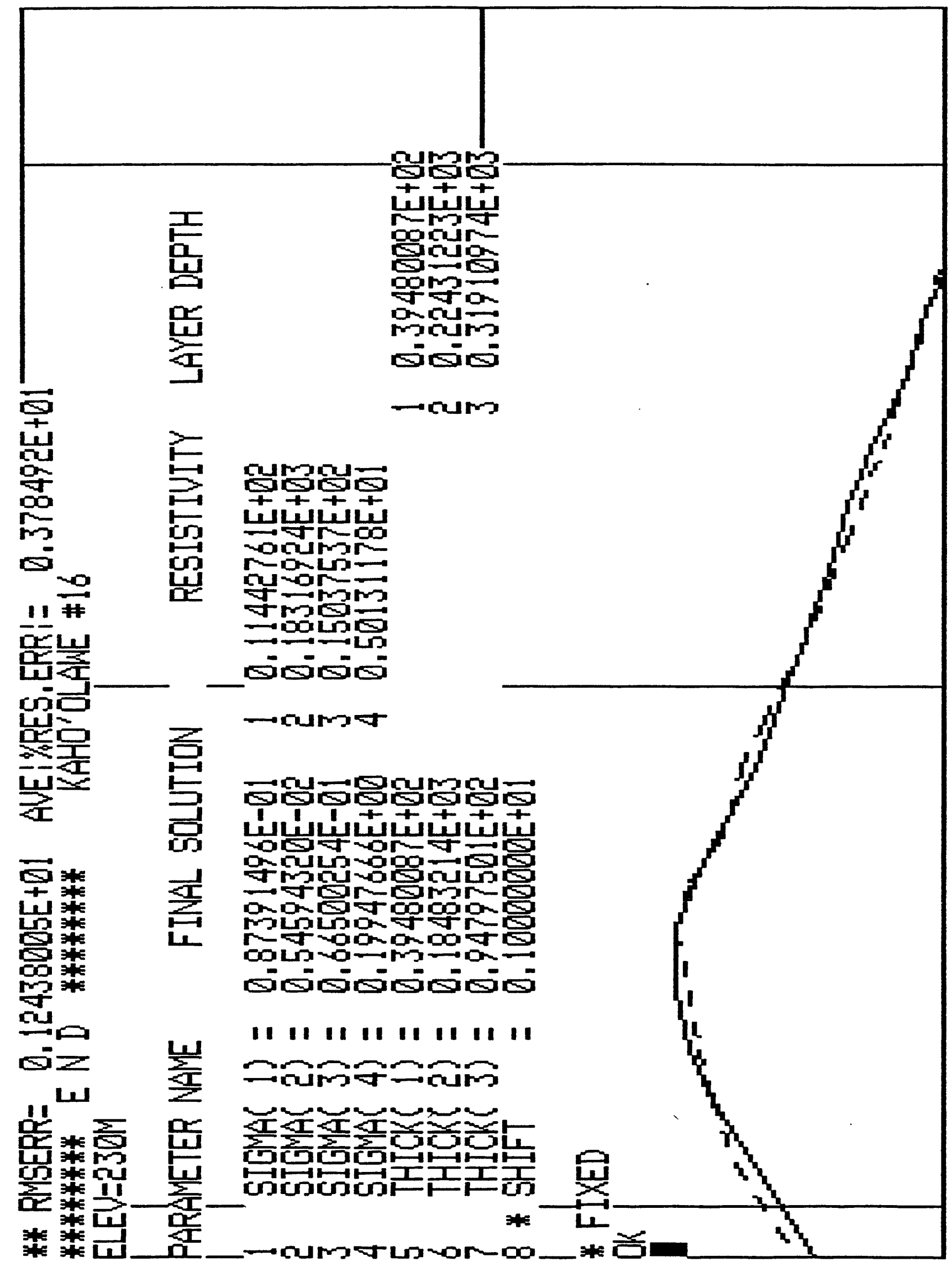




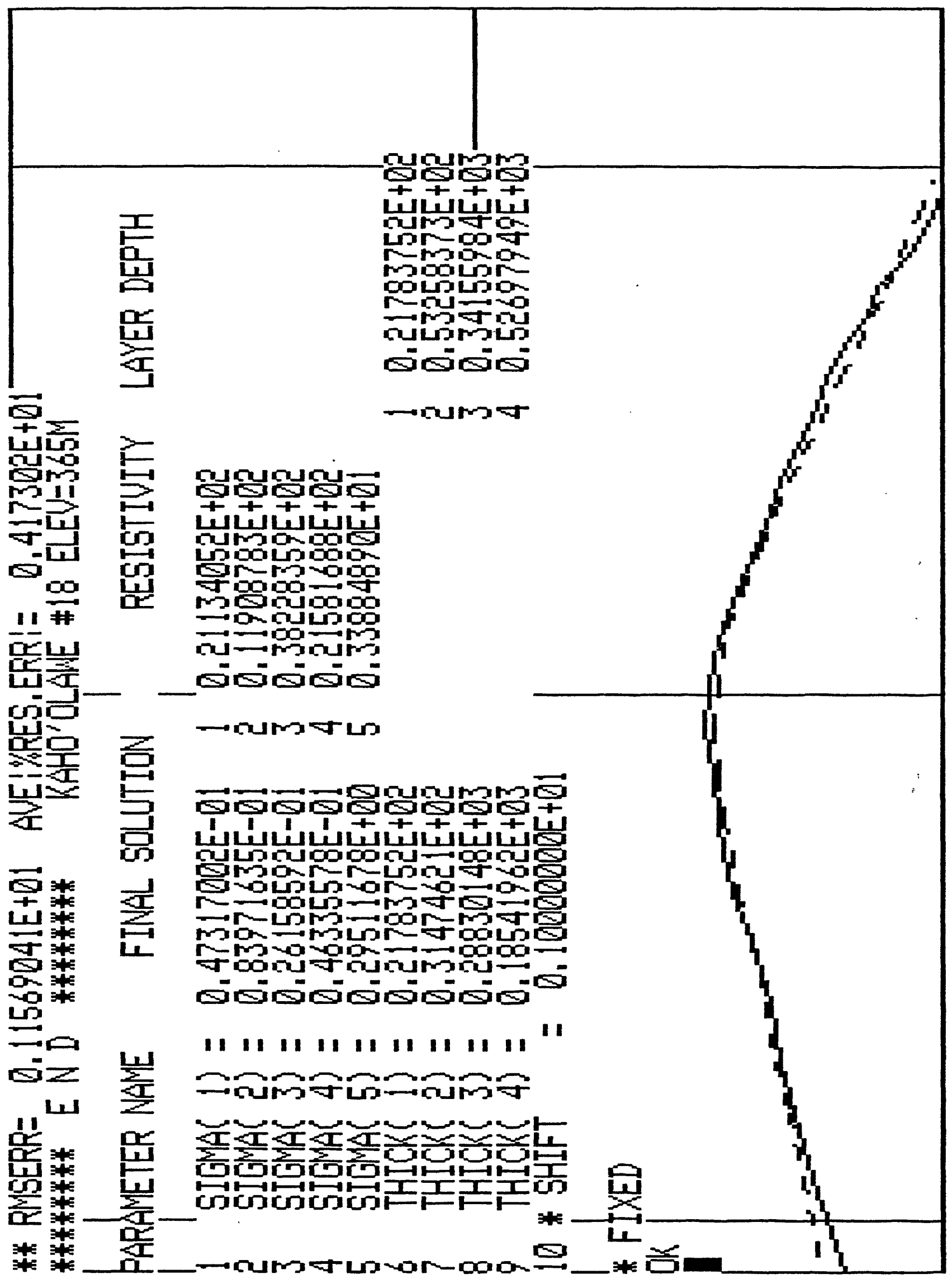




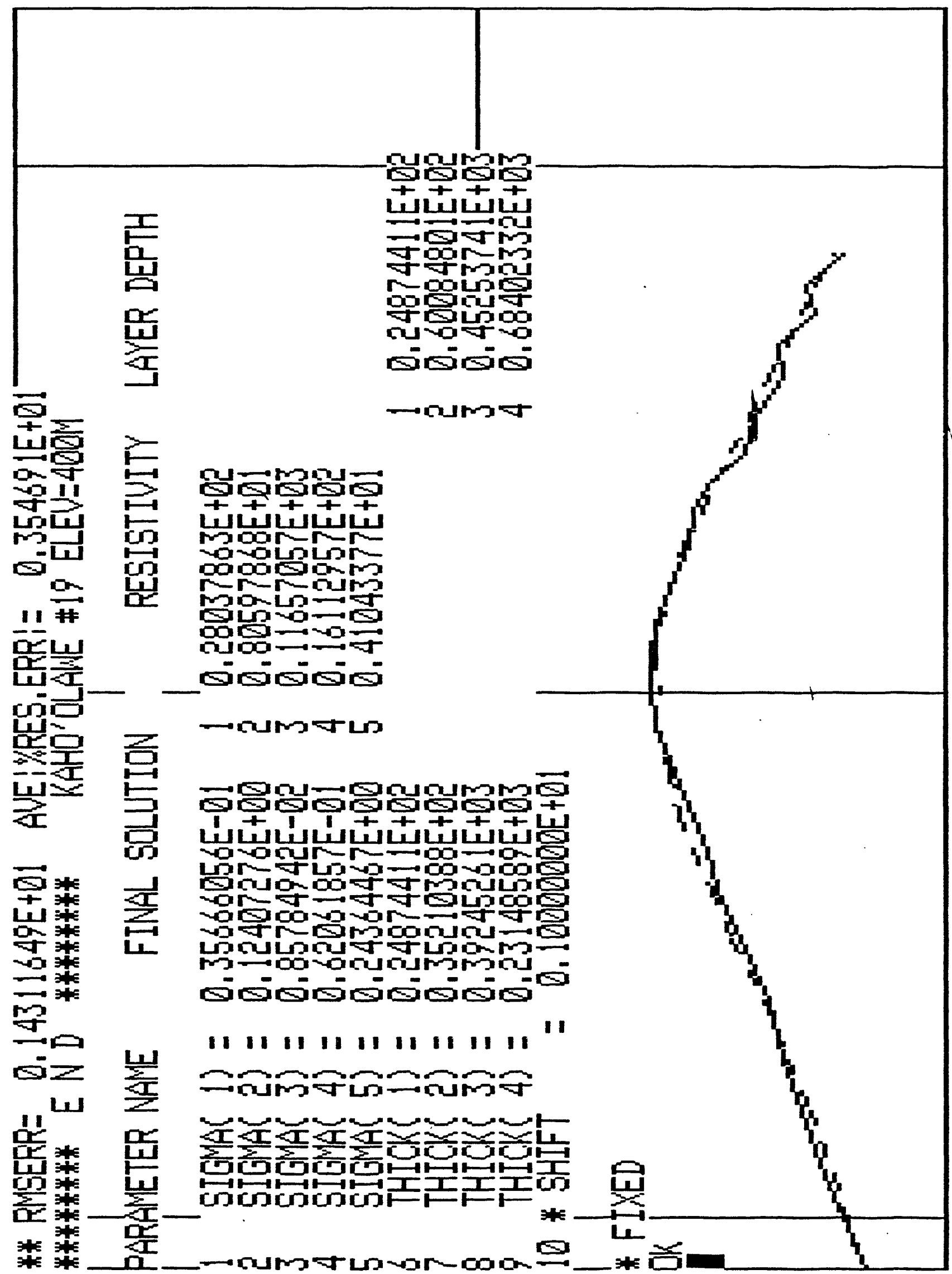





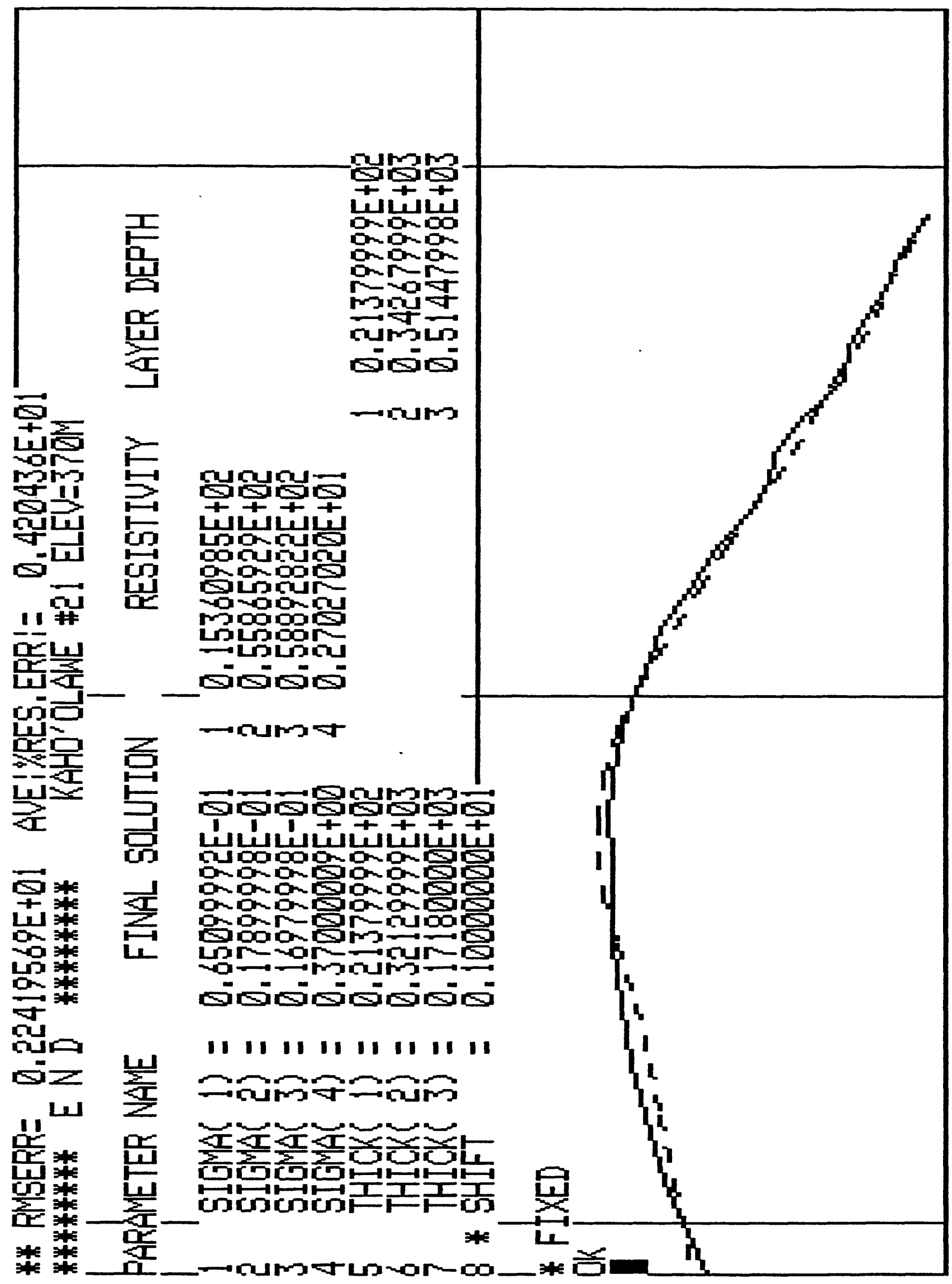




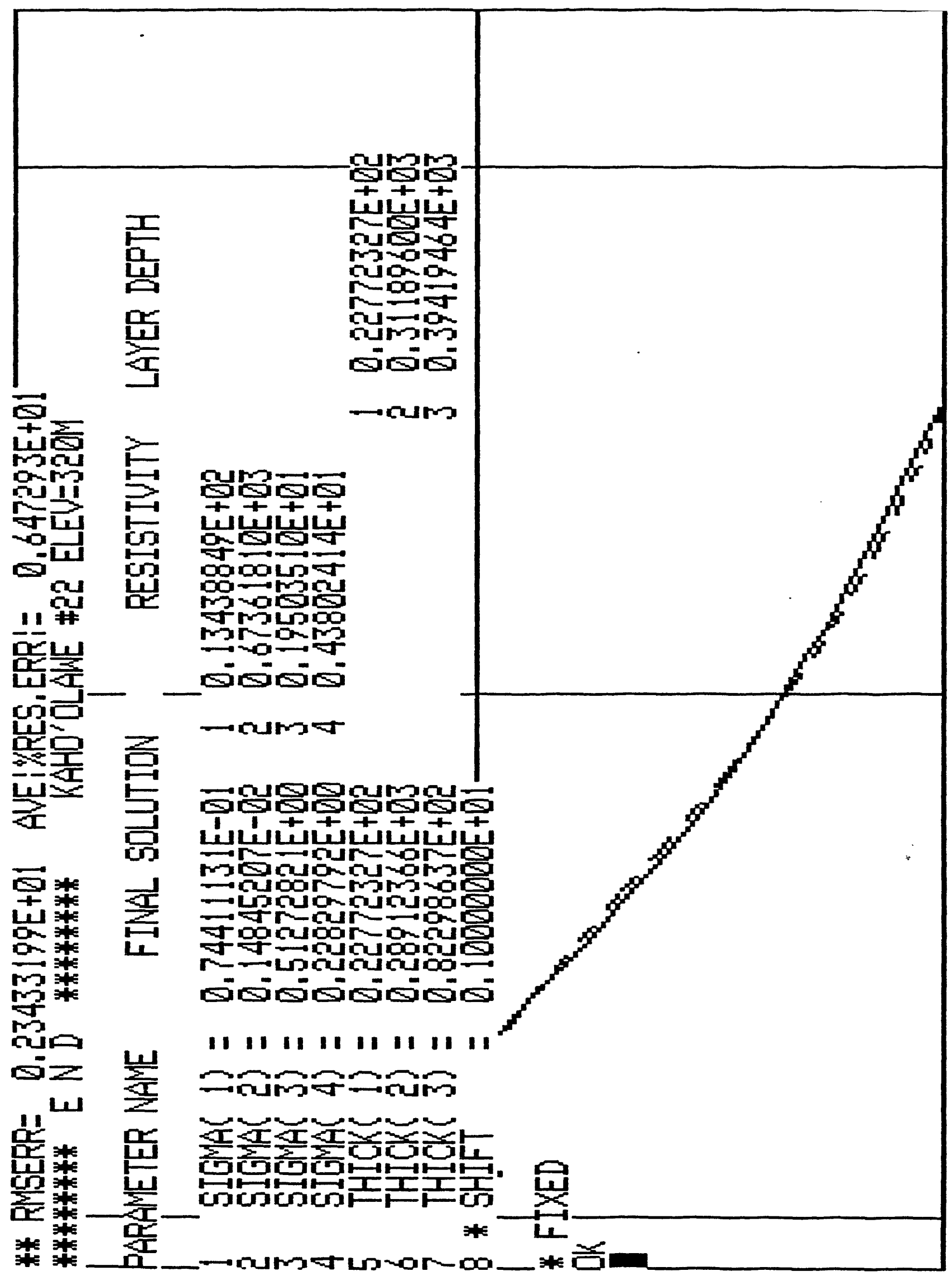




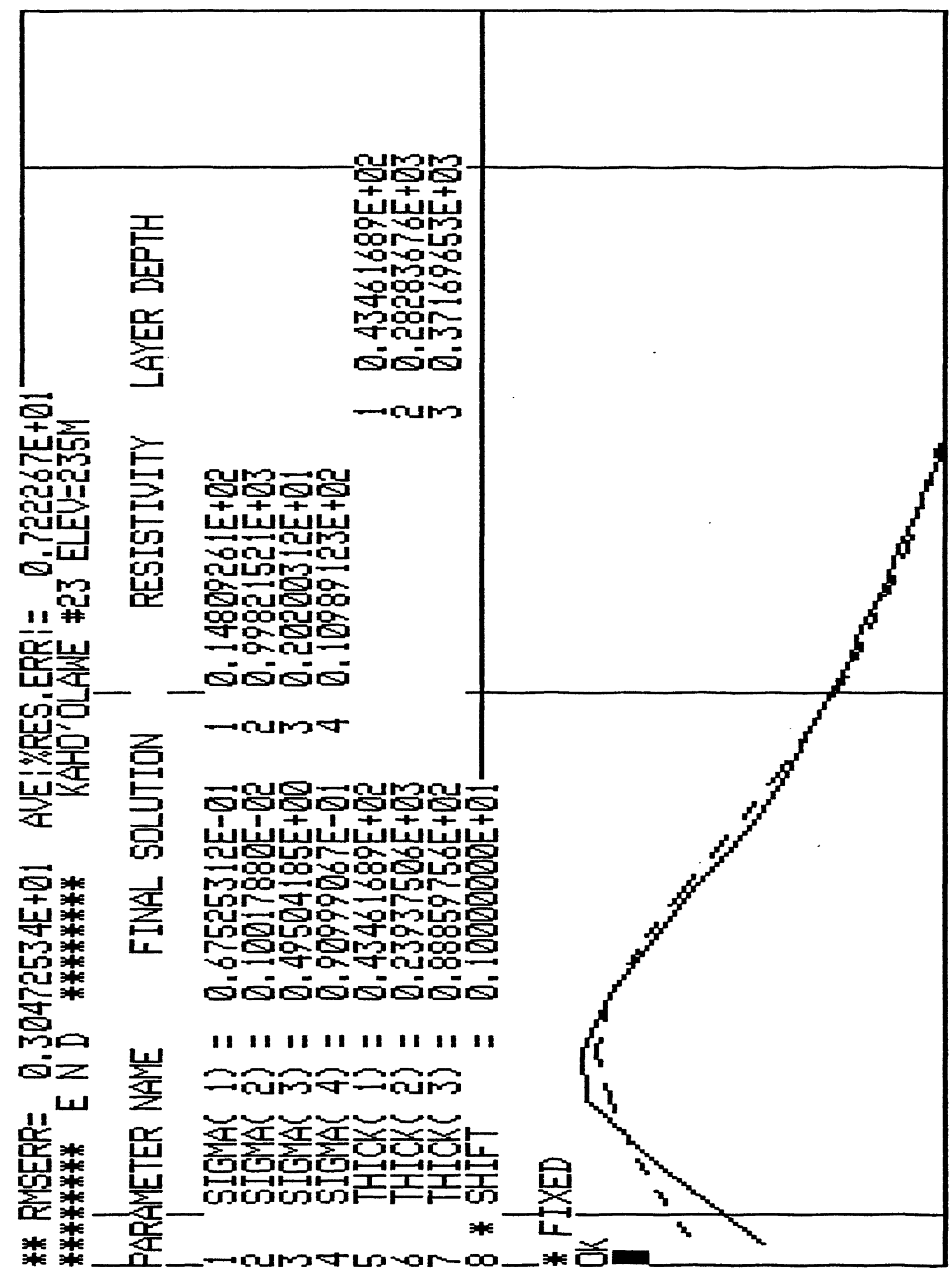

8.22 


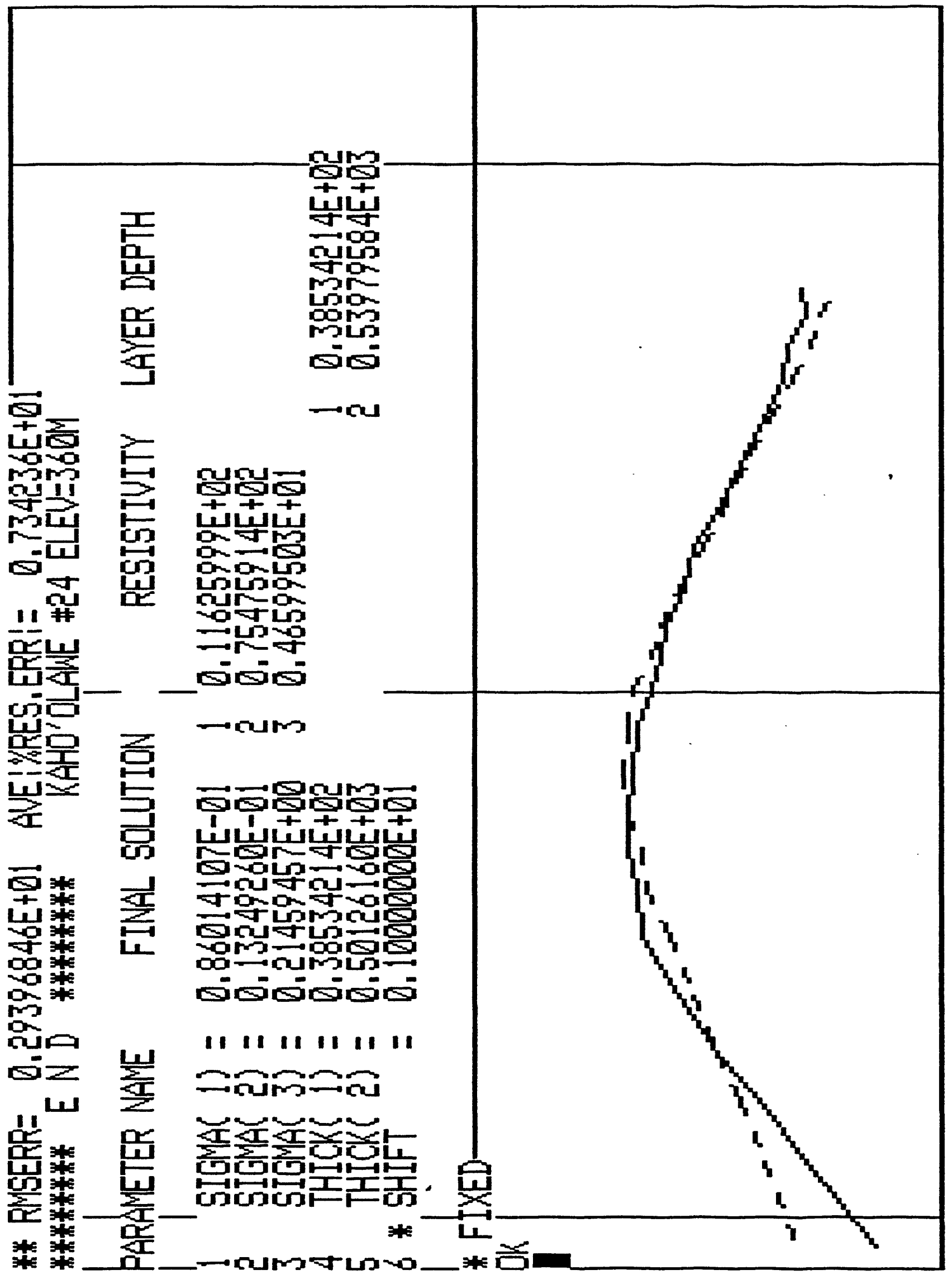




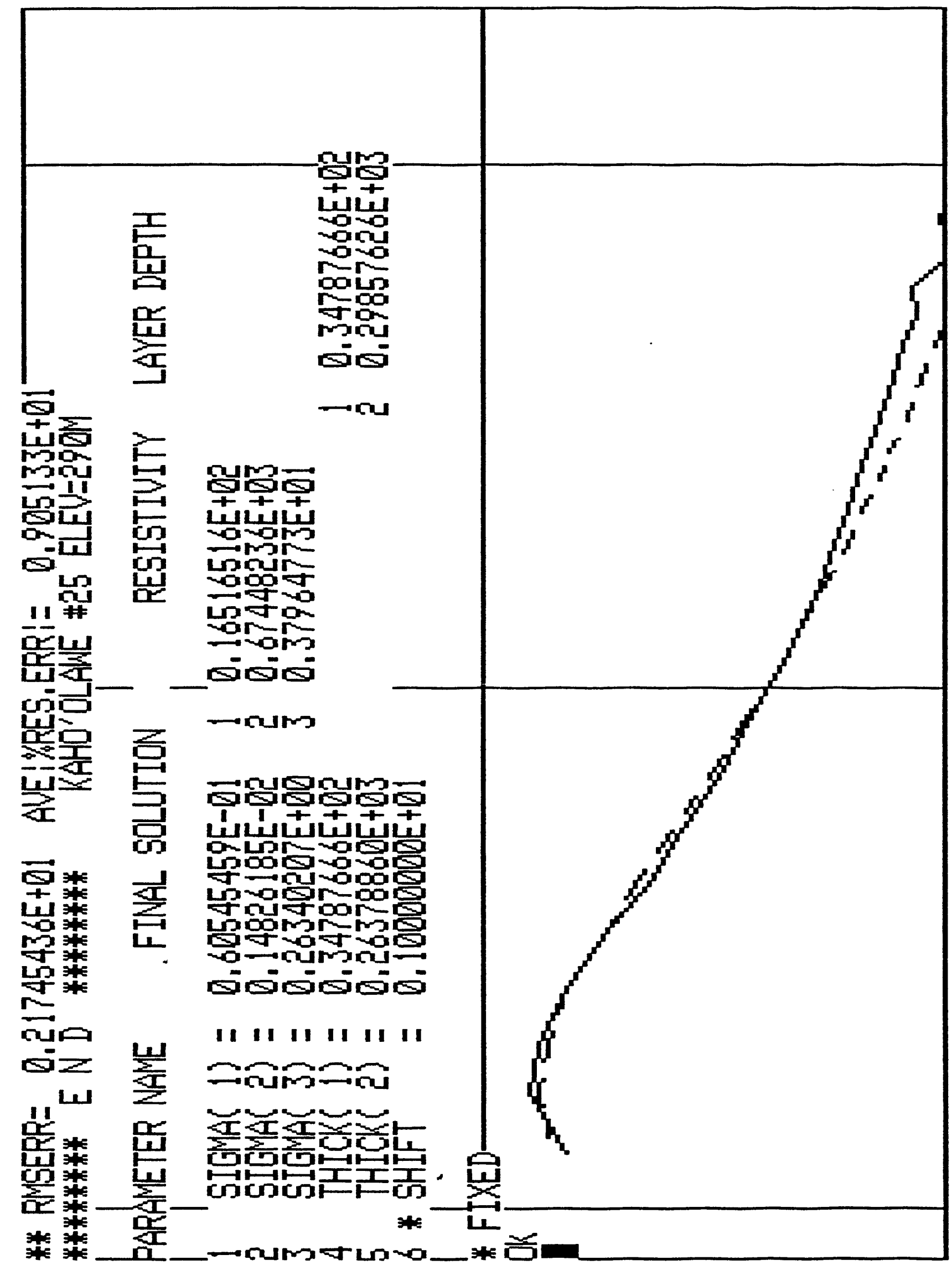

8.24 


\section{REFERENCES}

Anderson, W. L., 1979, Program MARQDCLAG -- Marquardt inversion of Dc-Schlumberger soundings by lagged-convolution: U.S. Geological Survey Open-File Report 79-1432, 58 p.

Anderson, W. L., 1982, Nonlinear least-squares inversion of transient soundings for a coincident loop system (Program NLSTCO), USGS Open-File Report 82-1064, 33 p.

Buselli, G., 1982, The effect of near-surface superparamagnetic material on electromagnetic measurements, Geophysics, v. 47, p. 1315-1324.

Fitterman, D.V. and Stewart, M.T., 1986, Transient electromagnetic sounding for groundwater, Geophysics, v. 51, p. 995-1005.

Fodor, R.V., Bauer, G.R., Jacobs, R.S., and Bornhorst, R.J., 1987, Kahoolawe Island, Hawaii: Tholeiitic, alkalic, and unusual hydrothermal(?) 'enrichment' characteristics, J. Volc. Geoth. Res., v. 31, p. 171-176.

Furumoto, A.S., 1965, A gravity survey of the Island of Kahoolawe, Hawaii, Pacific Science, v. 19, p. 94.

Kauahikaua, J. and Jackson, D.B., 1988, Mapping of an aquifer boundary near Kunia, O'ahu, Hawai'i using Schlumberger soundings, USGS Open-File Report 88-228, 14 p.

Macdonald, G.A., Abbott, A., and Peterson, F.L., 1983, Volcanoes in the Sea - The geology of Hawaii, University of Hawaii Press, Honolulu, Hawaii, 517 p.

Mattice, M.D., 1981, Geothermal and ground water exploration on Maui, Hawail by applying D.C. electrical soundings, Master's Thesis, University of Hawaii at Manoa, 80 p.

Newman, G.A., Anderson, W.L., and Hohmann, G.W., 1987, Interpretation of transient electromagnetic soundings over three-dimensional structure for the central-loop configuration, Geophys. J. R. Astr. Soc., v. 89 , p. $889-914$.

Raab, P.V., and Frischknecht, F.C., 1983, Desktop computer processing of coincident loop transient electromagnetic data, U.S. Geological Survey Open-File Report 83-240.

Rai, C.S. and Manghnani, M.H., 1981, The effects of saturant salinity and pressure on the electrical resistivity of Hawaiian basalts, Geophys. J. R. astr. Soc., v. 65, p. 395-405.

Stearns, H.T., 1940, Geology and Ground-water Resources of the islands of Lanai and Kahoolawe, Hawaii, Bulletin 6, Hawaii Div. of Hydrography, 177 p.

Strange, W.E., Woollard, G.P. and Rose, J.C., 1965, An analysis of the gravity field over the Hawailan Islands in terms of crustal structure, Pacific Science, v. 19, p. 381-389.

Swartz, J.H., 1937, Resistivity studies of some salt-water boundaries in the Hawailan Islands, Am. Geophys. Union Trans., 18th mtg., pt. 2, p. 387-393.

Takasaki, K. and Mink, J.F., 1985, Evaluation of major dike-impounded ground-water reservoirs, Island 
of Oahu, USGS Water-supply paper $2217,77 \mathrm{p}$.

Zohdy, A.A.R., and Bisdorf, R.J., 1989, Programs for the automatic processing and interpretation of Schlumberger sounding curves in QuickBASIC 4.0, U.S. Geological Survey Open-File Report 89-137 A \& B, 64 p. 


\section{List of Figures}

Figure 1. Map showing the location of Kaho'olawe in relation to the main islands of the state of Hawaii.

Figure 2. Map showing the location of Schlumberger and SIROTEM soundings on Kaho'olawe obtained during three trips in 1988. Pluses indicate SIROTEM sounding locations and double-headed arrows indicate Schlumberger sounding locations. Also shown are the four resistivity soundings reported by Stearns (1940) labelled A through D.

Figure 3. Comparison of the geophysical data interpretations from four pairs of coincident SIROTEM and Schlumberger soundings. a) Schlumberger sounding \#05 and SIROTEM sounding \#15 at the west edge of the study area, b) Schlumberger sounding \#04 and SIROTEM sounding \#07 at mid-island, c) Schlumberger sounding \#01 and SIROTEM sounding \#11 within the region where the conductive basement is depressed significantly below sea level, and d) Schlumberger sounding \#03 and SIROTEM sounding \#16 at the southern end of the island.

Figure 4. Map showing the distribution of weathered zone thicknesses from SIROTEM soundings on Kaho'olawe. The seven SIROTEM soundings in which the apparent resistivities increased too quickly with time are indicated by asterisks.

Figure 5. Map showing the distribution of unsaturated basalt resistivities on Kaho'olawe as determined by SIROTEM data.

Figure 6. Map showing the distribution of depths to the basement conductor beneath Kaho'olawe. Areas where that depth is greatest below sea level are considered to be the best prospect for potable ground water. Contour values are in meters below sea level.

Figure 7. A cross-sectional view of one theoretical model (Newman and others, 1987) showing a possible interpretation in terms of an aquifer with rectangular cross-section. 


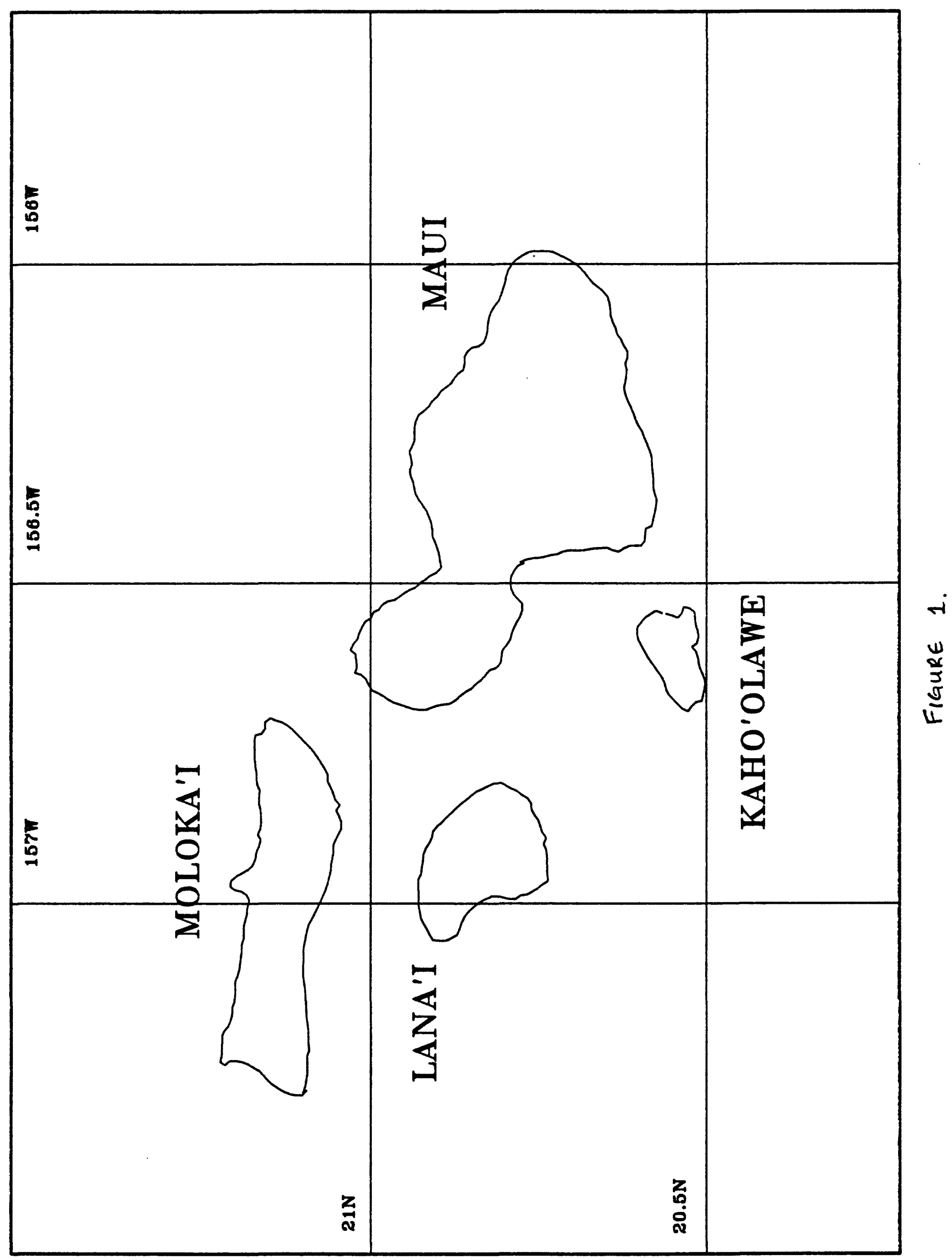

11.1 


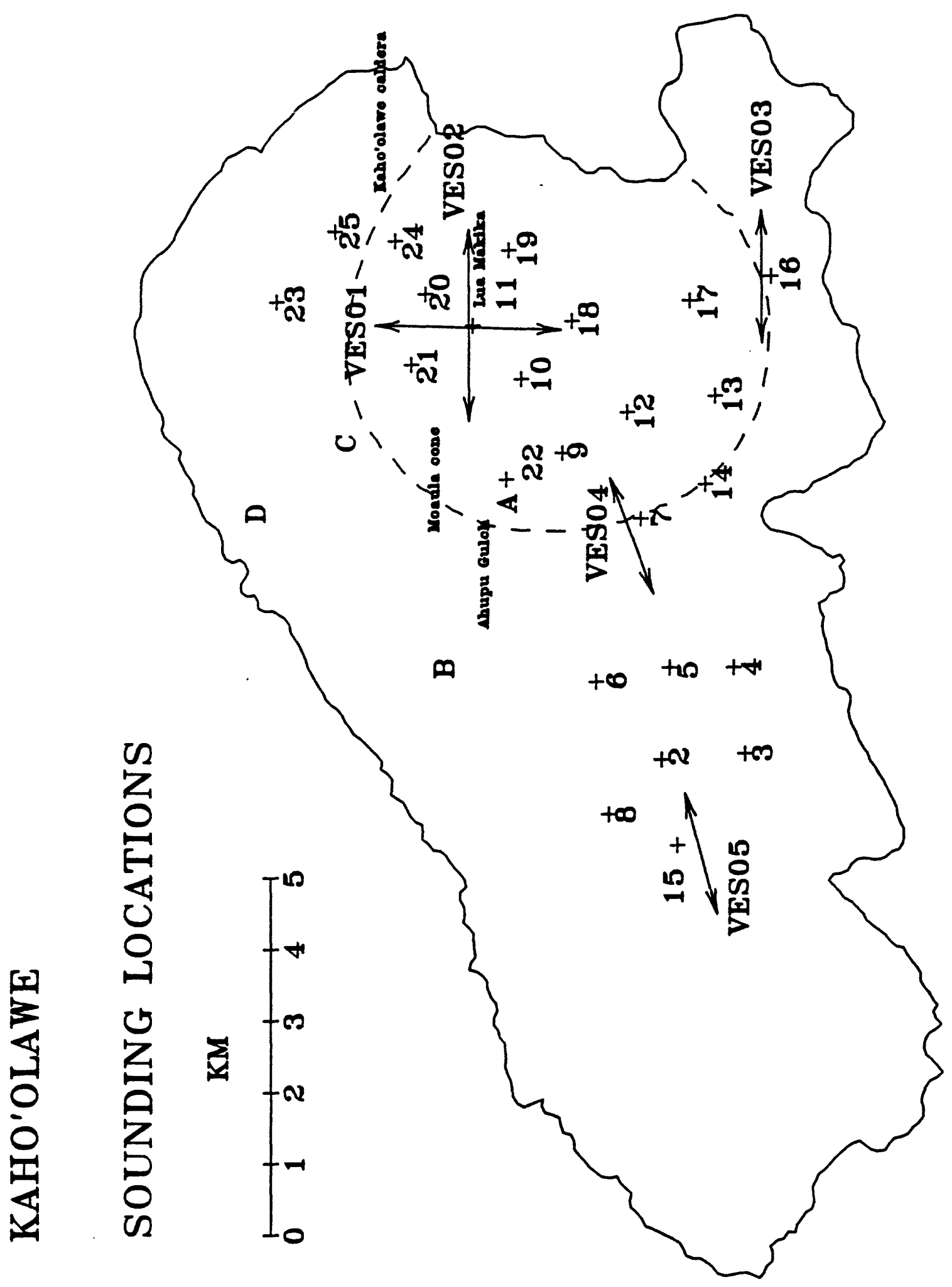

11.2 


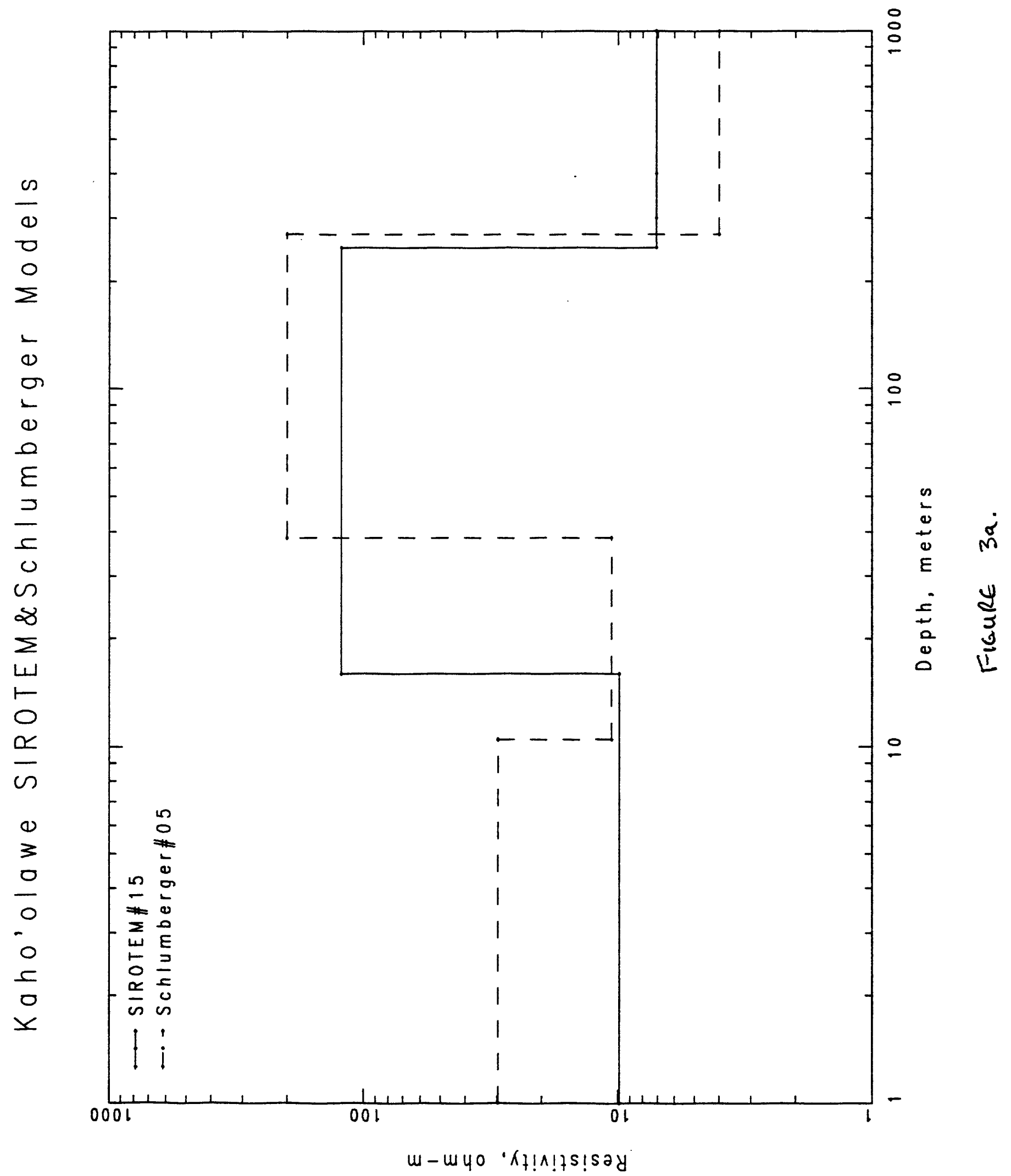

11.3 


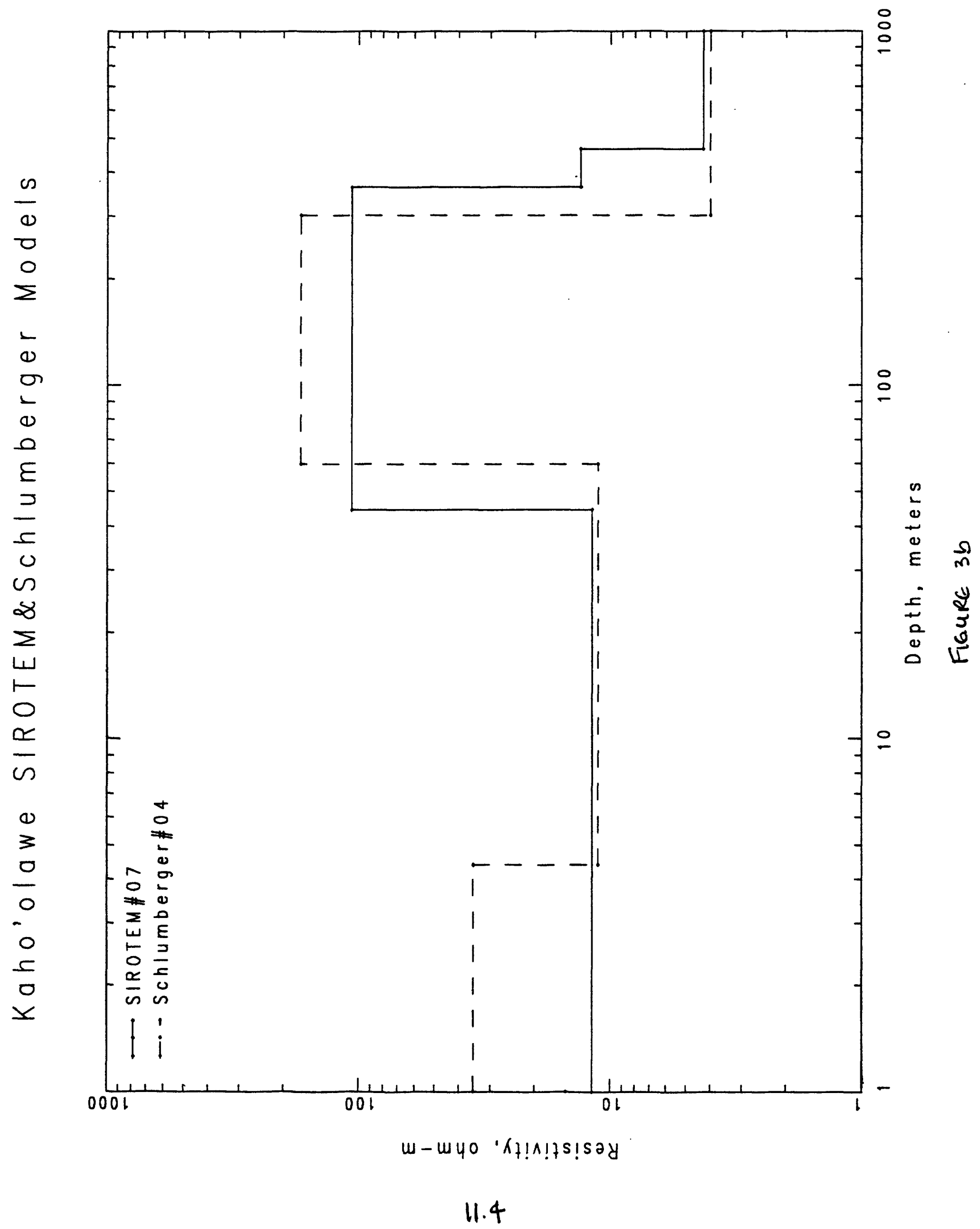




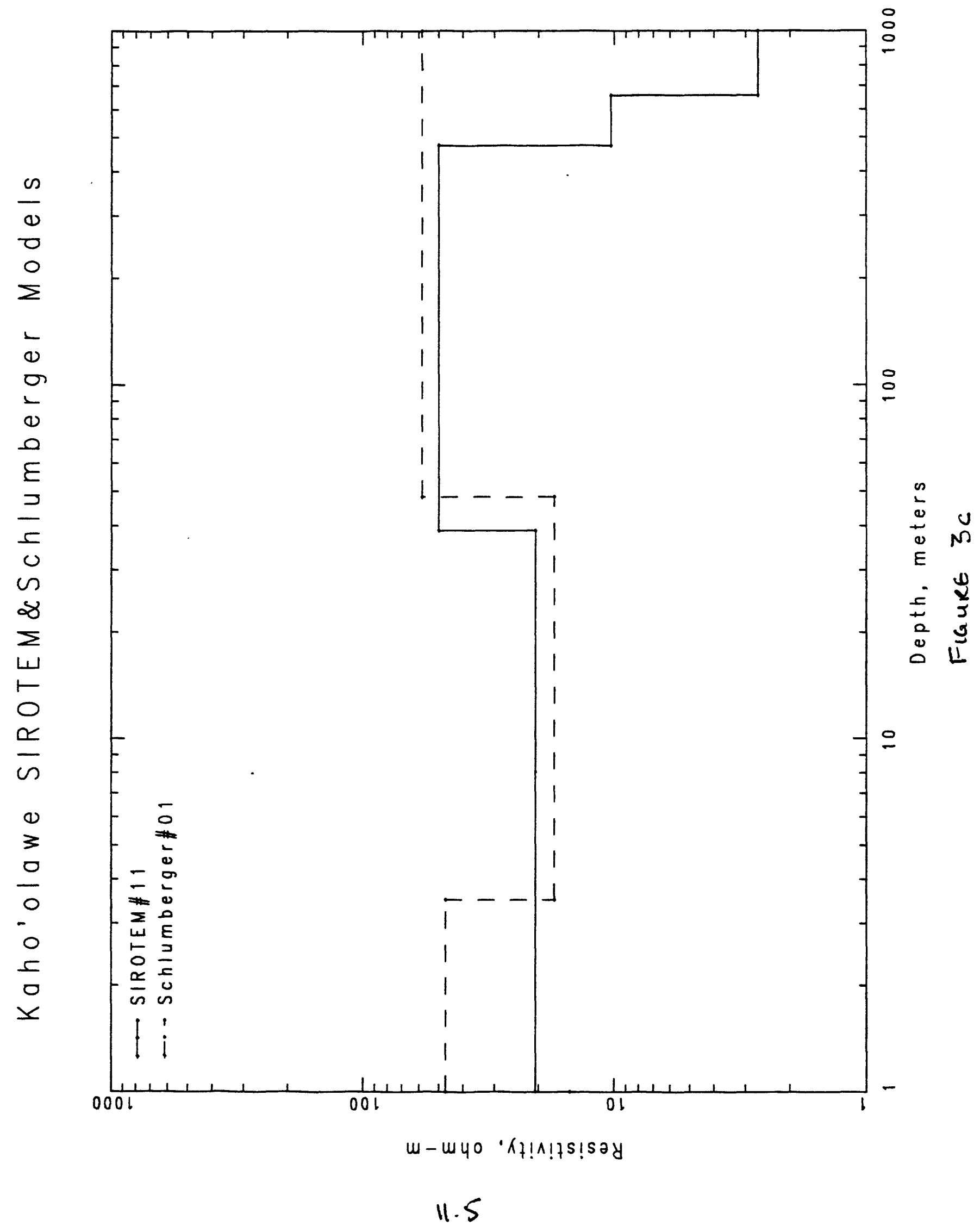




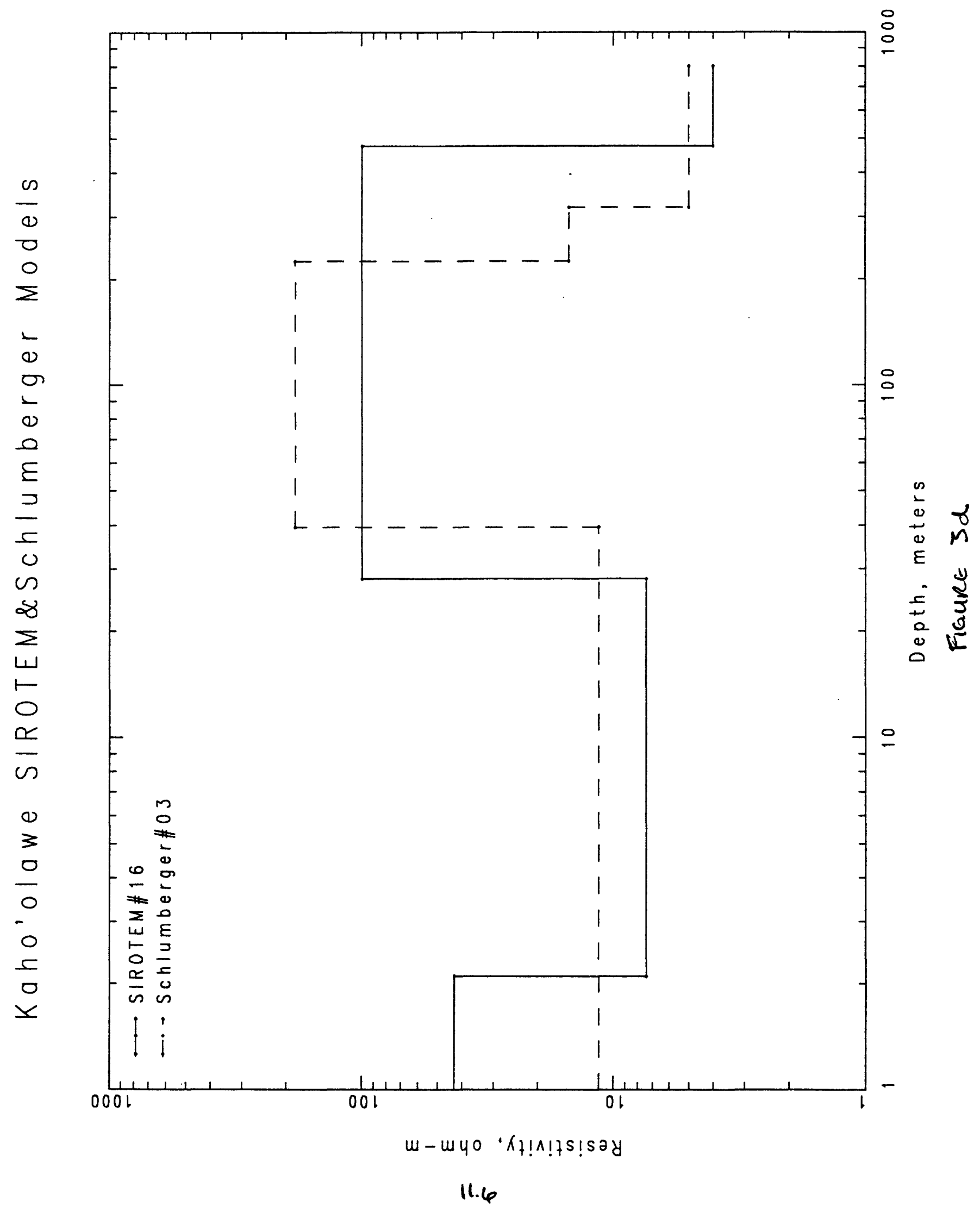




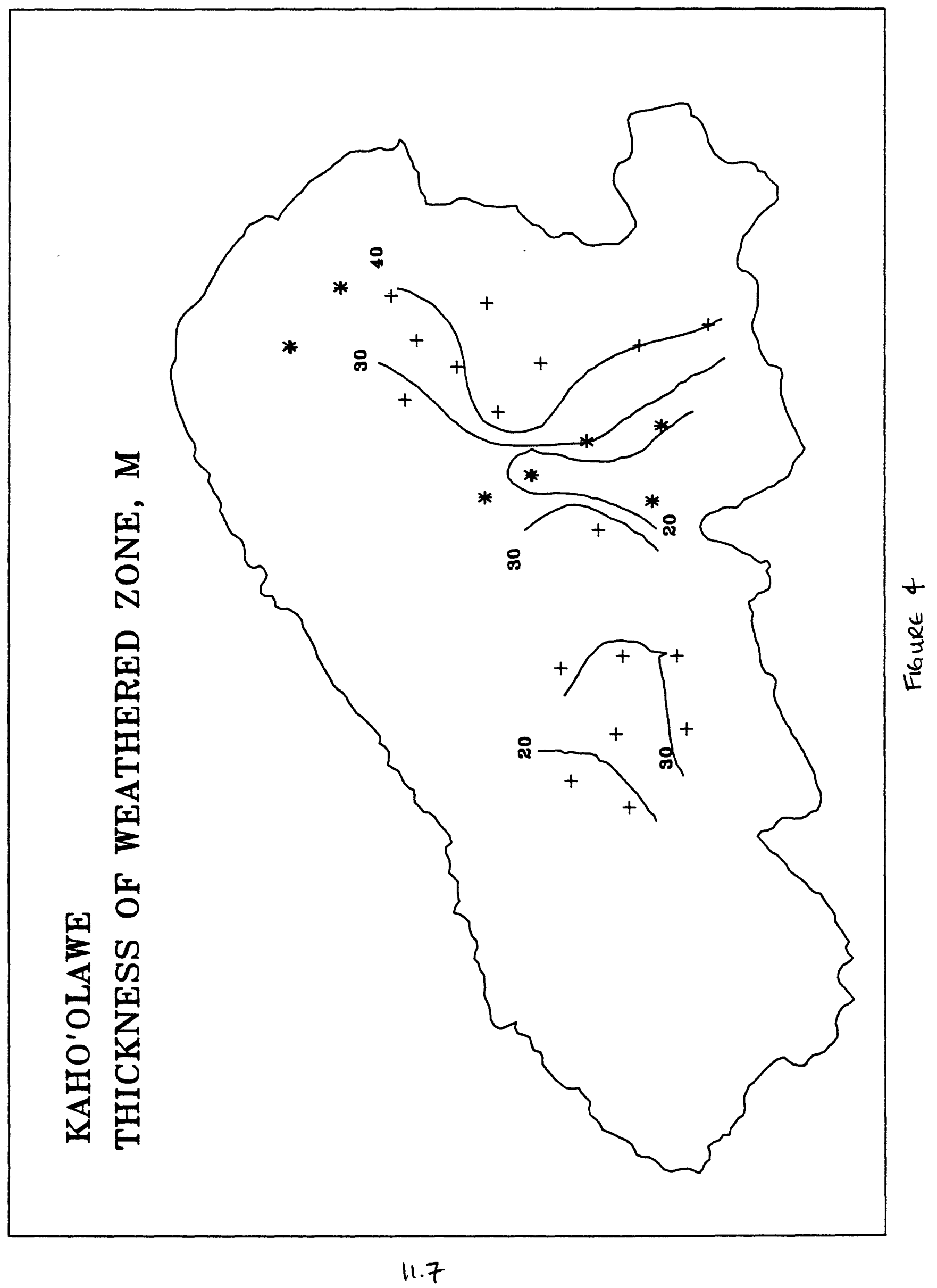




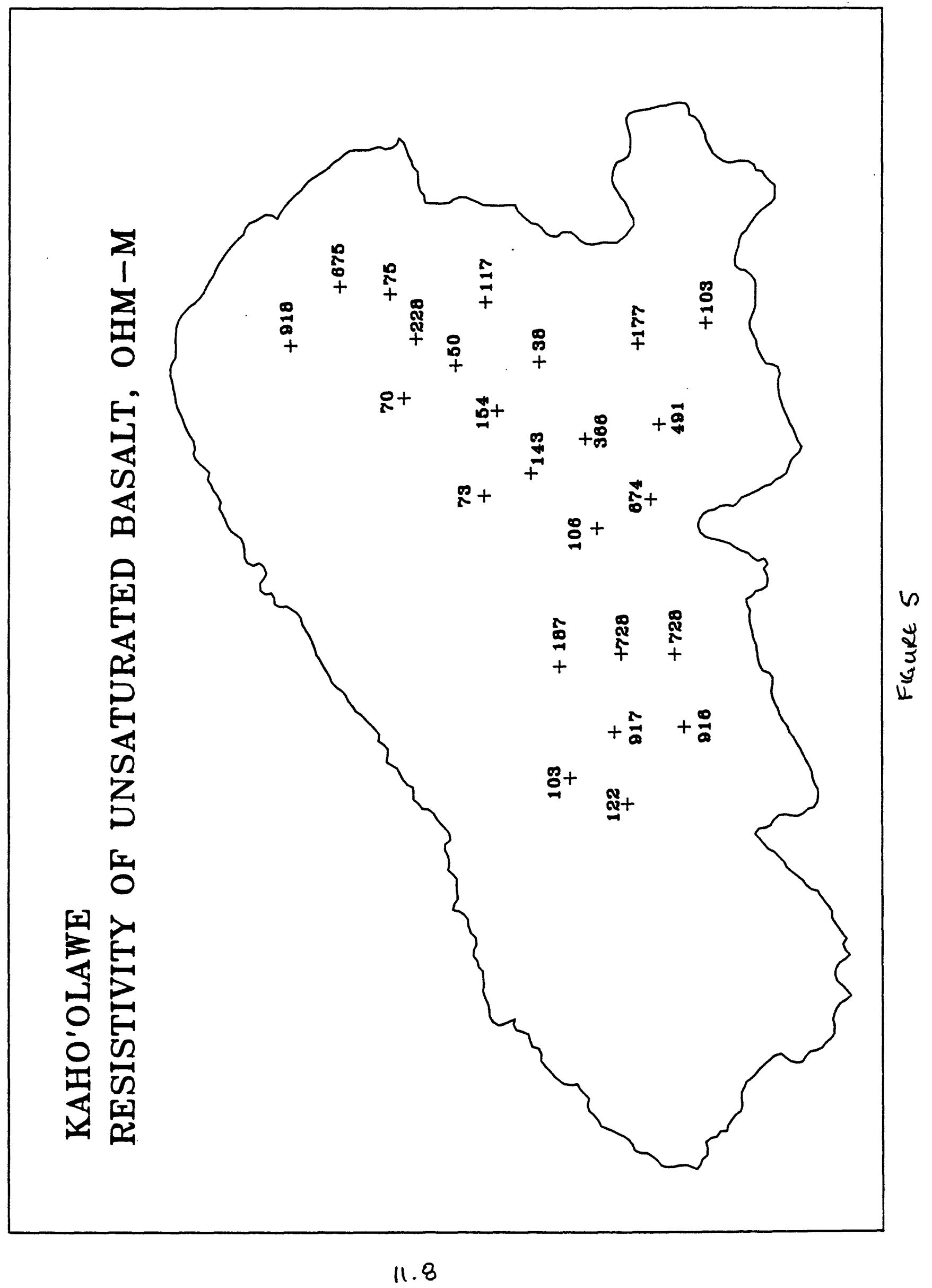




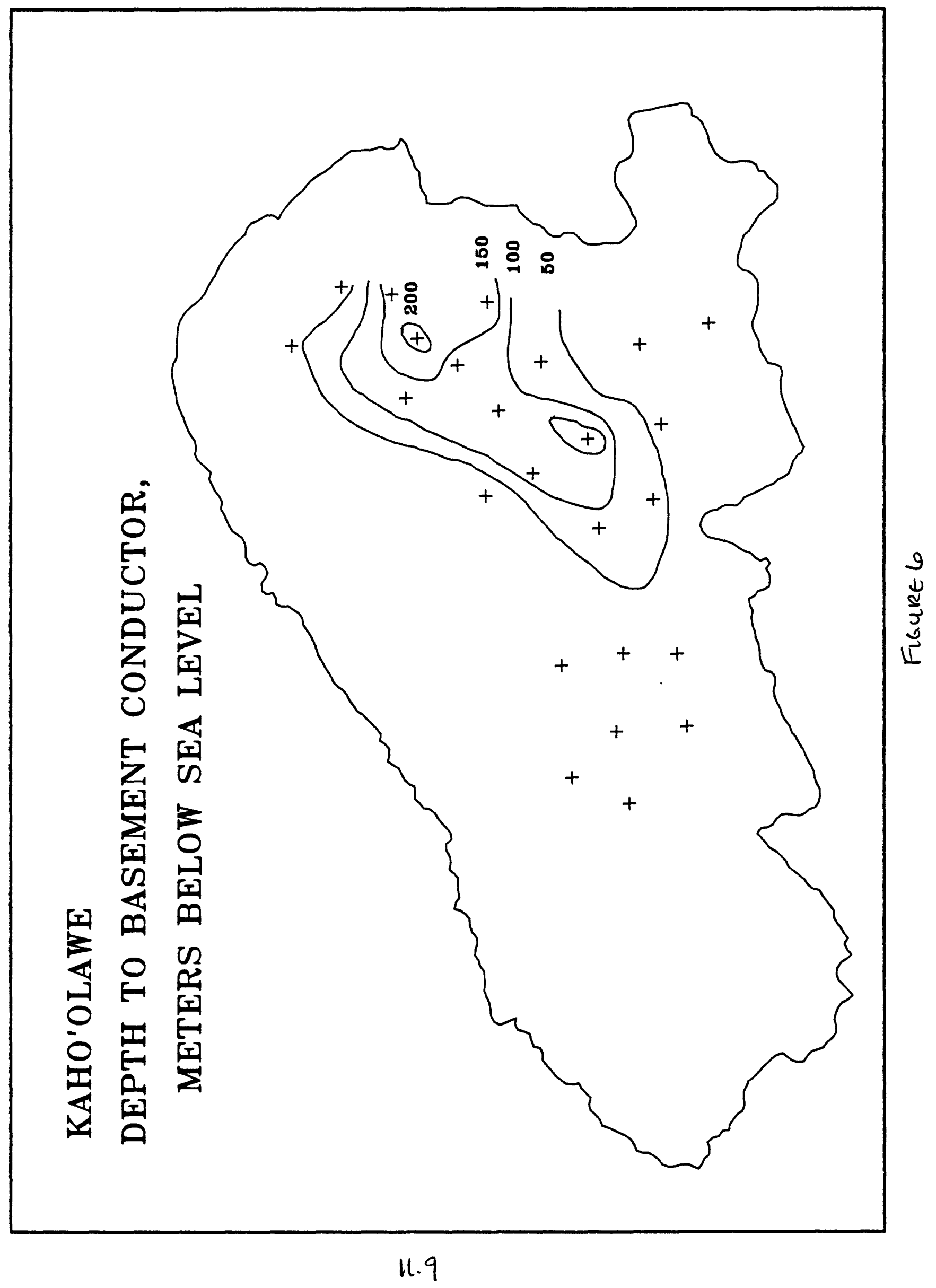




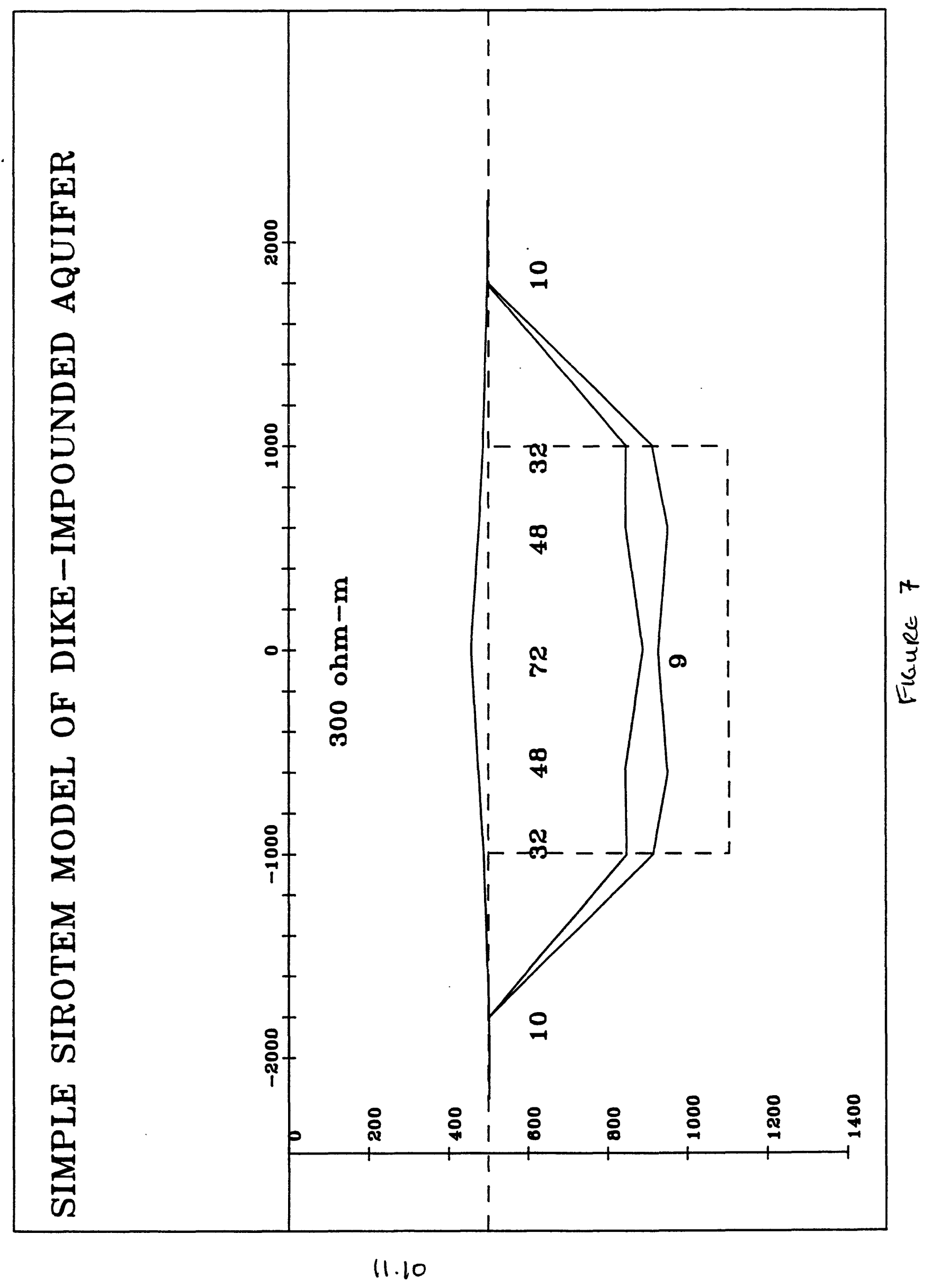


Table I: Kaho'olawe SIROTEM Interpretation Results

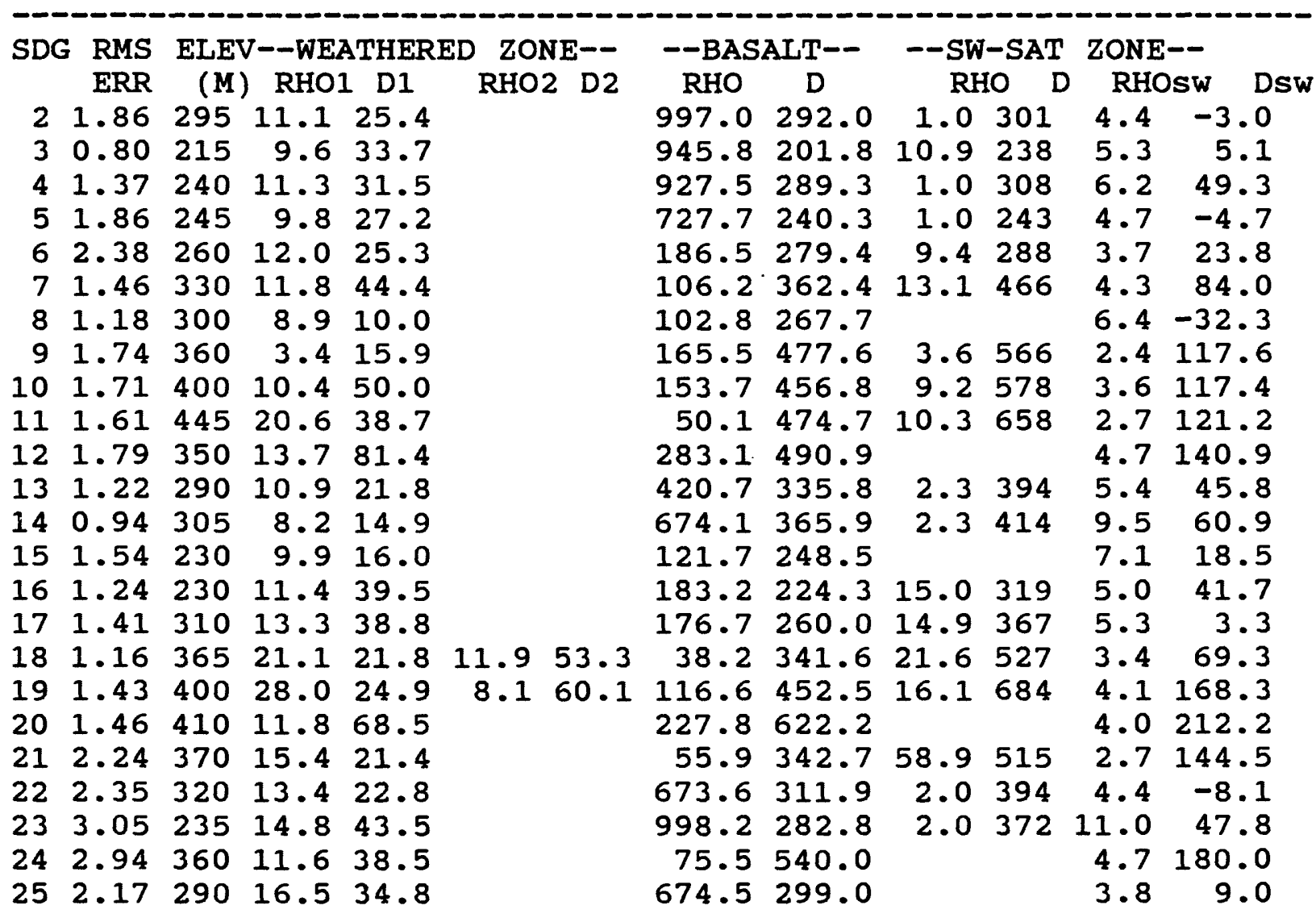

SDG sounding number

RMS ERR root-mean-square error, in percent

ELEV elevation of sounding, in meters

WEATHERED ZONE consists of one or two layers as needed. RHO1 and D1 are the resistivity and depth of layer bottom, respectively, of the first layer and RHO2 and D2 are the resistivity and depth to layer bottom of the second layer.

BASALT consists of one layer. RHO and D are the resistivity and depth to layer bottom, respectively of the layer.

SW-SAT ZONE sea water-saturated zone consists of one or two layers. RHO and D are the resistivity and depth to layer bottom of the first layer and RHOsw is the resistivity of the deepest layer detected. Dsw is the depth below sea level to the basement conductor if the SW-SAT ZONE consists of one layer. If it consists of two then Dsw will be the depth to the top of both layers if the upper resistivity is less than $10 \mathrm{ohm}-\mathrm{m}$. If the upper resistivity is greater than $10 \mathrm{ohm}-\mathrm{m}$, then Dsw is the depth to the midpoint of the upper layer. 